\title{
Surface Science Study of Water and Hydrogen Adsorbed on Rutile $\mathrm{TiO}_{2}(110)-(1 \times 1)$
}

Ke Cao

Liuzhou, China

Bachelor of Science, Peking University, 2011

A Thesis presented to the Graduate Faculty

of the University of Virginia in Candidacy for the Degree of

Master of Science

Department of Chemistry

University of Virginia

January, 2014 


\section{ABSTRACT}

The dissociative adsorption of water at oxygen-vacancy defect sites on the $\mathrm{TiO}_{2}(110)$ surface spatially redistributes the defect electron density originally present at subsurface sites near the defect sites. This redistribution of defect-electrons makes them more accessible to $\mathrm{Ti}^{4+}$ ions surrounding the defects. The redistribution of electron density decreases the $\mathrm{O}^{+}$desorption yield from surface lattice $\mathrm{O}^{2-}$ ions in $\mathrm{TiO}_{2}$, as excited by electron stimulated desorption (ESD). A model in which $\mathrm{OH}$ formation on defect sites redistributes defect electrons to neighboring $\mathrm{Ti}^{4+}$ sites is proposed. This switches off the Knotek-Feibelman mechanism for ESD of $\mathrm{O}^{+}$ions from lattice sites. Conversely, enhanced $\mathrm{O}^{+}$reneutralization could also be induced by redistribution of defect electrons. The redistribution of surface electrons by adsorption is further verified by the use of donor and acceptor molecules which add or remove electron density.

We have found a new form of chemically-bound hydrogen on the $\mathrm{TiO}_{2}(110)$ surface $\left(\mathrm{H} / \mathrm{TiO}_{2}\right)$, which is produced by exposure to atomic $\mathrm{H}$ at $87 \mathrm{~K}$. This chemisorbed hydrogen differs significantly in its physical properties from $\mathrm{OH} / \mathrm{TiO}_{2}$ produced by $\mathrm{H}_{2} \mathrm{O}$ adsorption. The $\mathrm{H} / \mathrm{TiO}_{2}$ species produces a normal beam of $\mathrm{H}^{+}$upon electron stimulated desorption whereas $\mathrm{OH} / \mathrm{TiO}_{2}$ species produce inclined $\mathrm{H}^{+}$ESD beams. An inclined $\mathrm{O}-\mathrm{H}$ bond in $\mathrm{OH} / \mathrm{TiO}_{2}$ results in an elliptic $\mathrm{H}^{+}$ion angular distribution pattern. $\mathrm{H} / \mathrm{TiO}_{2}$ is thermally less stable than $\mathrm{OH} / \mathrm{TiO}_{2} . \mathrm{By} \sim 350 \mathrm{~K}, \mathrm{H} / \mathrm{TiO}_{2}$ has disappeared, probably by thermal 
desorption or diffusion into the bulk, whereas $\mathrm{OH} / \mathrm{TiO}_{2}$ begins to desorb as $\mathrm{H}_{2} \mathrm{O}$ only above $\sim 350 \mathrm{~K}$. 


\section{ACKNOWLEGMENTS}

I sincerely thank my advisor, Prof. John T. Yates, Jr. for his intellectual support and continual encouragement through my studies. This thesis was made possible by his patience and persistence. John has very rich knowledge and experience in teaching physical chemistry and surface science research. I was deeply inspired by his active involvement in class as well as his critical and rigorous spirit in scientific research.

I thank Dr. Zhen Zhang for his continual support and teaching me all the ultra-high vacuum system operation skills, as well as his help in my daily life. His rich knowledge and experience in surface science study impressed me and I learned very much from him.

I am grateful to Prof. Ion Harrison, who gave me good suggestions when I encountered problems. I would like to thank Prof. Kevin K. Lehmann, Prof. Eric Herbst, Prof. Sergei A. Egorov and Prof. Petra Reinke, for their excellence in teaching me profound knowledge in chemistry and materials.

I also wish to thank my lab mates, including Dr. Michael Büttner, Dr. Mahesh Rajappan, Dr. Isabel Green, Dr. Lynn Mandeltort, Ana Stevanovic, Chunqing Yuan, Monica McEntee and Shiliang Ma, for their help in the laboratory as the coworkers.

I am also thankful to Prof. David H. Metcalf, who provided help with ultraviolet test of filters in his course lab. 
I want to thank my parents and my sister for their support of my studying abroad. Their encouragement and support drives me forward all the time.

Finally, full support for the project from DOE, Office of Basic Energy Science, under grant number DE-FG02-O9ER16080 is gratefully acknowledged. 


\section{Table of Contents}

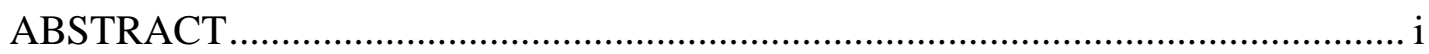

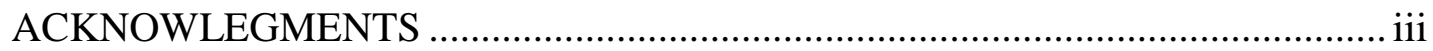

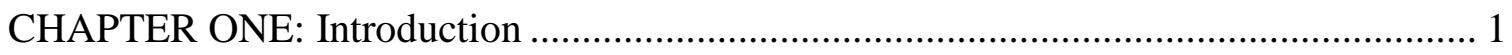

$1.1 \mathrm{TiO}_{2}$ Applications and $\mathrm{TiO}_{2}(110)$ Surface ................................................... 1

1.1.1 Rutile $\mathrm{TiO}_{2}(110)$ Structure .......................................................... 1

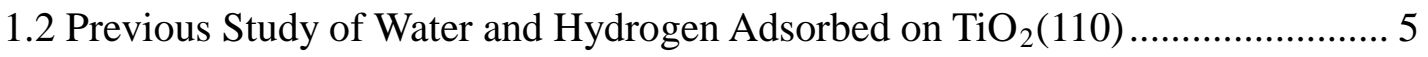

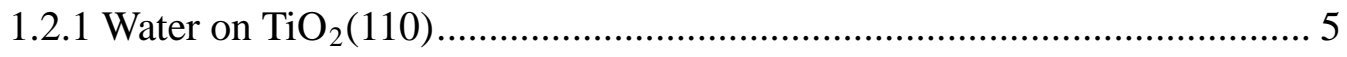

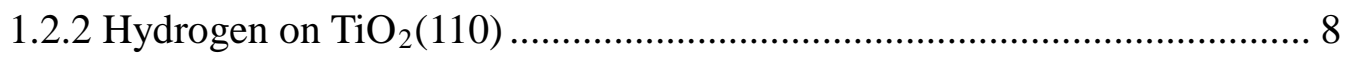

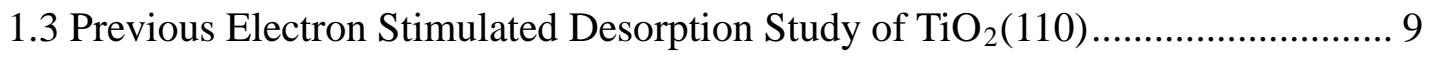

1.4 Electron Stimulated Desorption Mechanisms.............................................. 10

1.4.1 Menzel-Gomer-Redhead (MGR) Mechanism .................................... 10

1.4.2 Knotek-Feibelman (K-F) Mechanism.............................................. 12

CHAPTER TWO: Instrumentation and Sample Details ............................................ 15

2.1 Ultra-high Vacuum Apparatus................................................................... 15

2.2 Instrumentation, Methods and Sample Details ............................................. 15 
2.2.1 Time-of-flight Electron Stimulated Desorption Ion Angular Distribution16

2.2.2 Low Energy Electron Diffraction....................................................... 18

2.2.3 Auger Electron Spectroscopy......................................................... 19

2.2.4 Quadrupole Mass Spectrometer ......................................................... 21

2.2.5 Temperature Programmed Desorption ................................................. 22

2.2.6 Photon Stimulated Desorption ........................................................... 23

$2.3 \mathrm{TiO}_{2}$ Sample Mounting, Cleaning and Preparation ....................................... 24

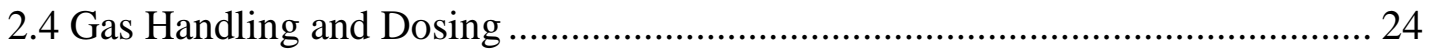

CHAPTER THREE: Defect-Electron Spreading on the $\mathrm{TiO}_{2}(110)$ Semiconductor Surface

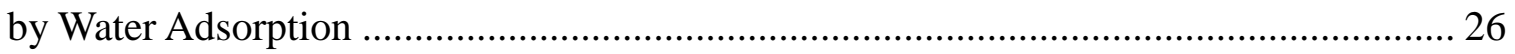

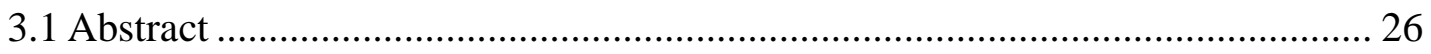

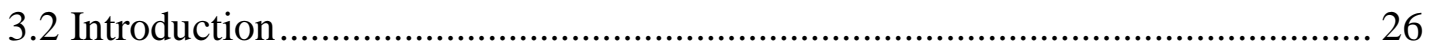

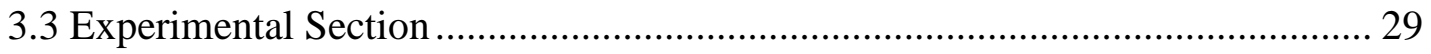

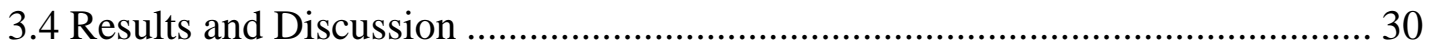

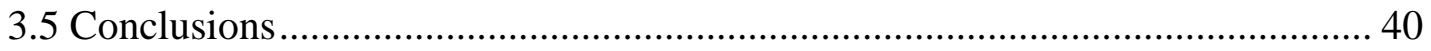

CHAPTER FOUR: A New Form of Chemisorbed Atomic H on the $\mathrm{TiO}_{2}(110)$ Surface . 42 


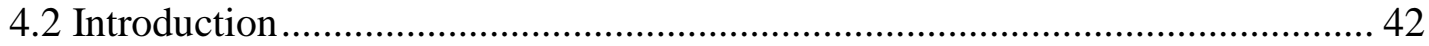

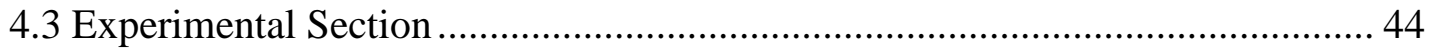

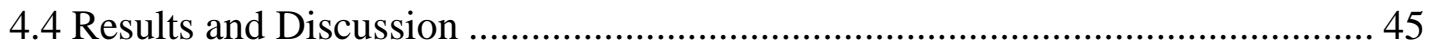

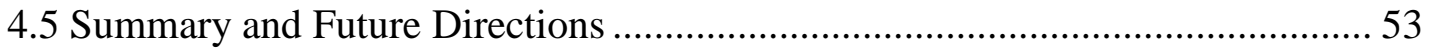

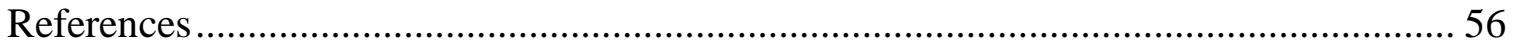

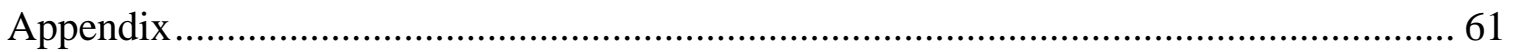

Appendix A: UV-Vis Spectra of Selected Longpass Filters and Bandpass Filters ... 61 



\section{CHAPTER ONE: Introduction}

\section{1 $\mathrm{TiO}_{2}$ Applications and $\mathrm{TiO}_{2}(110)$ Surface}

Titanium dioxide $\left(\mathrm{TiO}_{2}\right)$ is one of the most promising semiconductor materials in diverse applications. Notably, the discovery of photocatalytic splitting of water on $\mathrm{TiO}_{2}$ electrodes by Fujishima and Honda in 1972 started a new era of $\mathrm{TiO}_{2}$ study ${ }^{[1]}$. In 1991, O’Regan and Gratzel first reported nanocrystalline $\mathrm{TiO}_{2}$ dye-sensitized solar cell (DSSC) with an efficiency of 7.1-7.9\% under simulated solar light ${ }^{[2]}$, which was another milestone in the history of research of $\mathrm{TiO}_{2}$. Besides photocatalytic water splitting and DSSC, $\mathrm{TiO}_{2}$ has sparked extensive research interests, including photocatalytic degradation of organic polluntants $^{[3]}$, gas sensors ${ }^{[4-5]}$, self-cleaning coating ${ }^{[6]}$, and UV-induced hydrophilicity ${ }^{[7]}$.

\subsubsection{Rutile $\mathrm{TiO}_{2}(110)$ Structure}

Titanium dioxide exists mainly in three phases in nature: anatase, rutile and brookite.

The lattice structure of anatase and rutile $\mathrm{TiO}_{2}$ is shown in Figure 1.1, and brookite is not used often in research. Both of the structures of rutile and anatase can be described in terms of distorted $\mathrm{TiO}_{6}$ octahedra chains. The octahedron in rutile shows a slight orthorhombic distortion, while in anatase, the octahedron is significantly distorted and has a lower symmetry than orthorhombic ${ }^{[8]}$. 

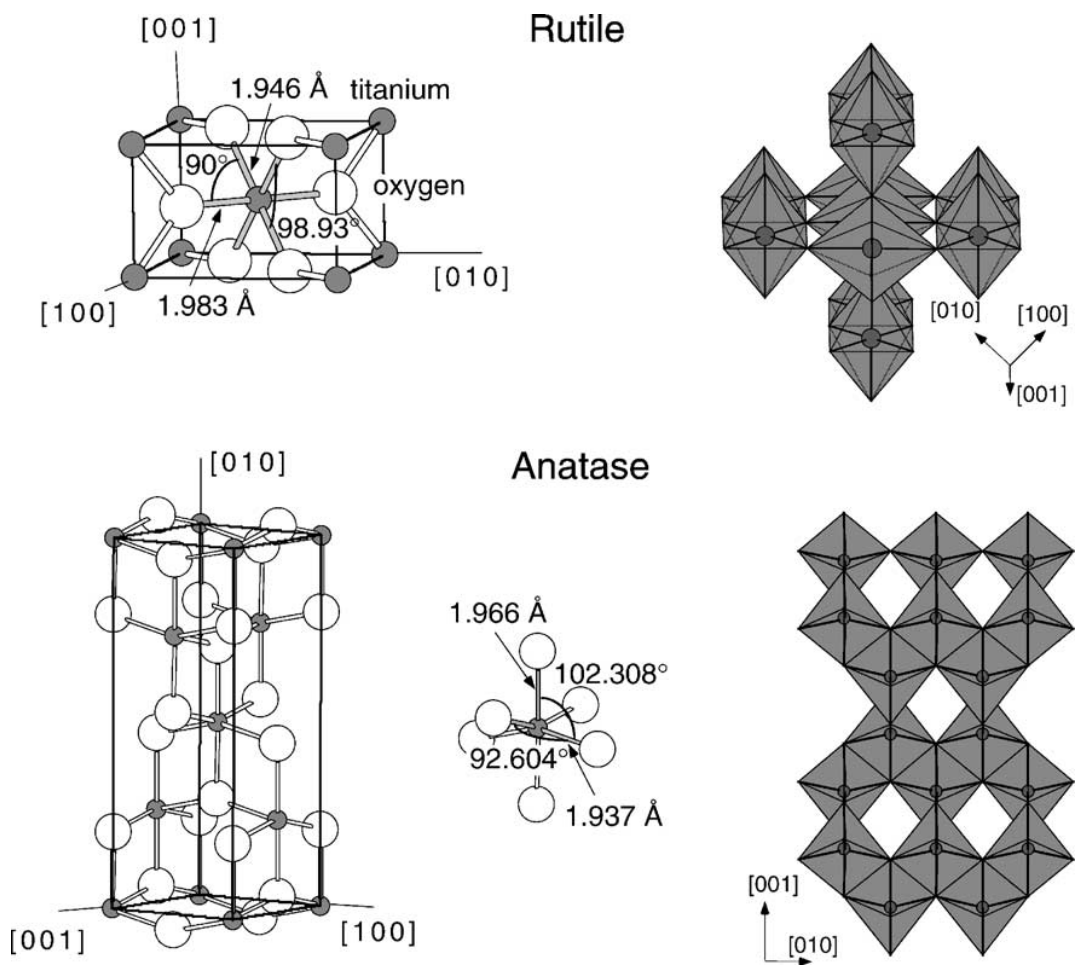

Figure 1.1: Lattice structure of rutile and anatase $\mathrm{TiO}_{2}$, showing bond lengths and bond angles. Figure is reproduced from Reference ${ }^{[9]}$.

Crystalline rutile has three low-index faces, (110), (100) and (001). A diagram of these faces is shown in Figure 1.2. Among them, (110) is the most thermally stable face and thus the most studied. 

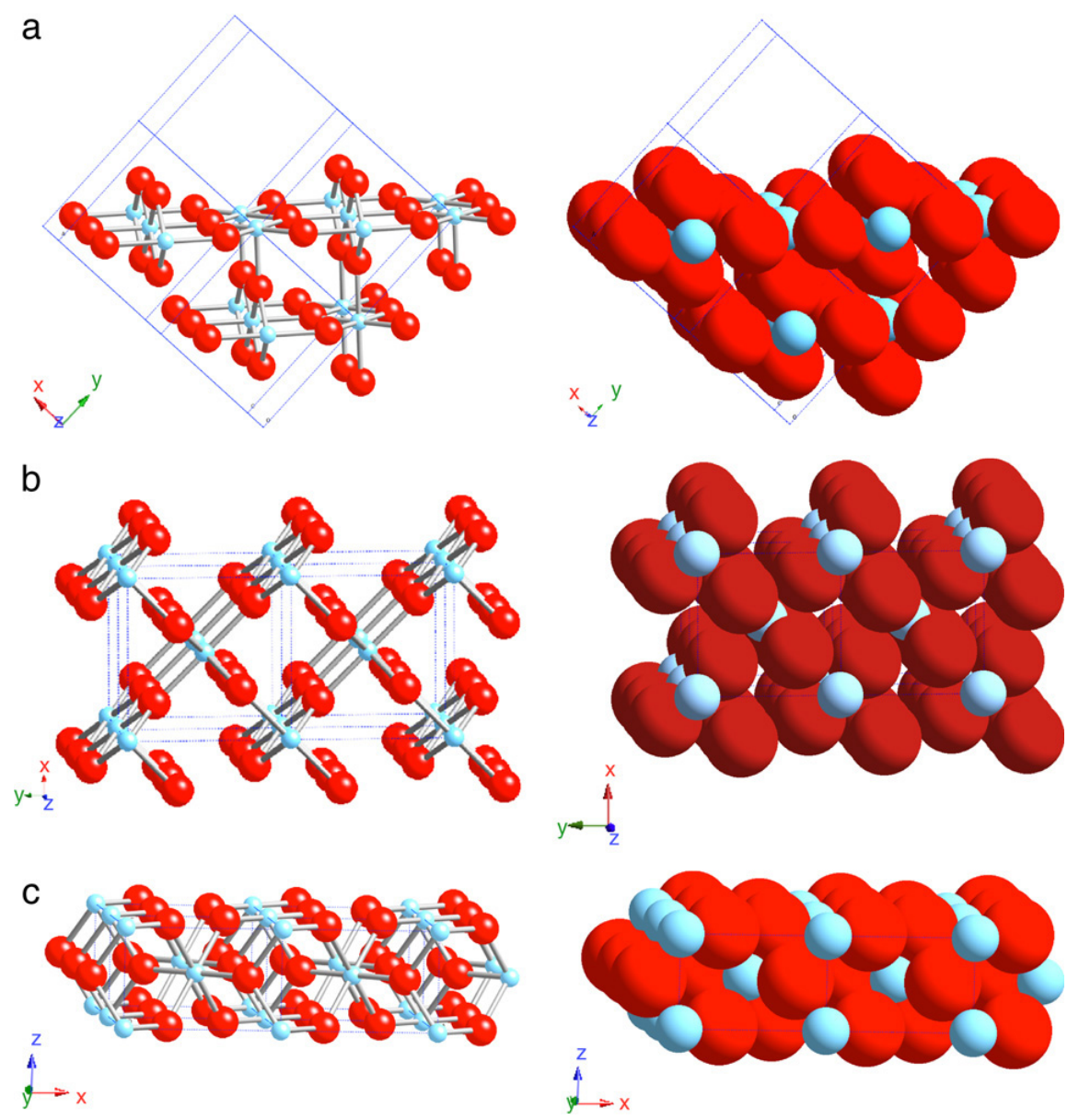

Figure 1.2: Schematic diagram of faces of rutile: (a)(110); (b)(100); (c)(001). Figure is reproduced from Reference ${ }^{[10]}$.

\subsubsection{1 $\mathrm{TiO}_{2}(110)-(1 \times 1)$}

The rutile $\mathrm{TiO}_{2}(110)-(1 \times 1)$ surface with some known point defects is shown in Figure 1.3. The surface contains rows of bridge-bonded oxygen (BBO) atoms that lie above the in-plane surface. Bridge-bonded oxygen vacancy (BBOV) sites are usually generated by sputtering and annealing ${ }^{[9]}$. The BBO rows are located on top of 6-fold coordinated $\mathrm{Ti}\left(\mathrm{Ti}_{6 \mathrm{c}}\right)$ 
rows, which are in the same plane as 5 -fold coordinated $\left(\mathrm{Ti}_{5 \mathrm{c}}\right)$ rows. The rows of in-plane oxygen atoms separate $\mathrm{Ti}_{5 c}$ and $\mathrm{Ti}_{6 c}$ rows.

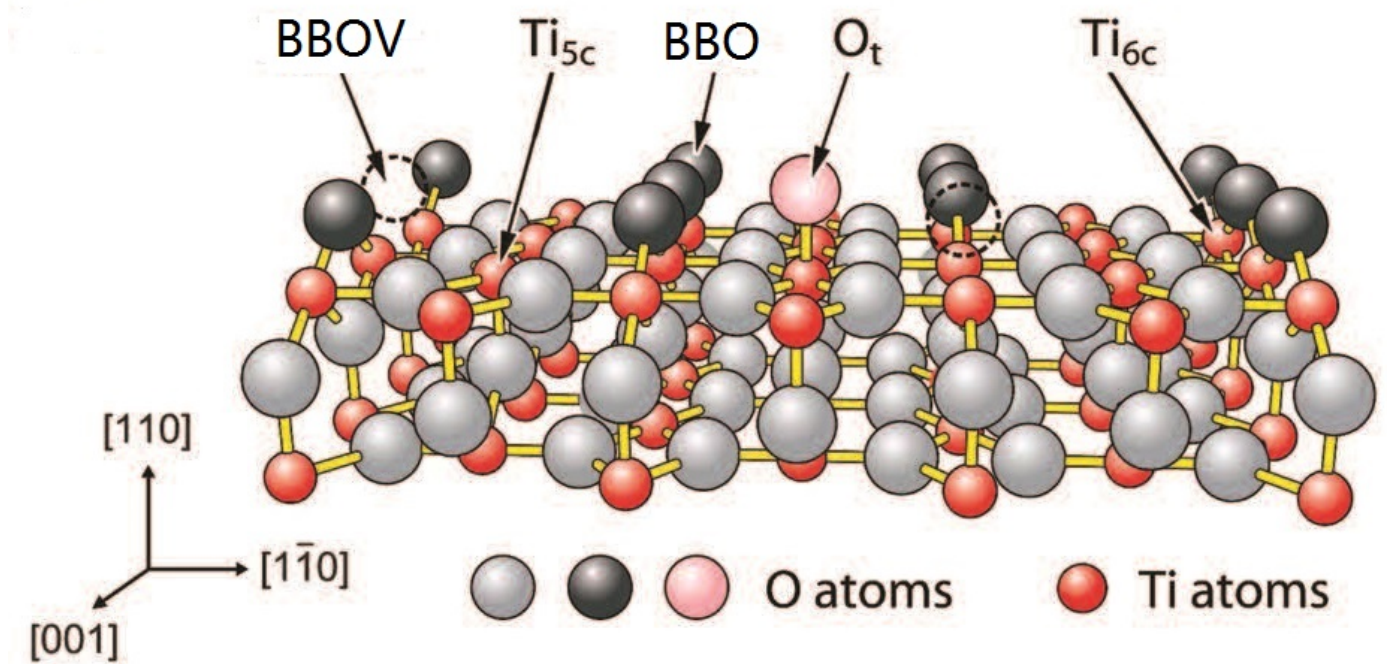

Figure 1.3: Ball-and-stick model of rutile $\mathrm{TiO}_{2}(110)-(1 \times 1)$ surface with some point defects. Figure is modified from Reference ${ }^{[11]}$.

\subsubsection{2 $\mathrm{TiO}_{2}(110)-(1 \times 2)$}

A $\mathrm{TiO}_{2}(110)-(1 \times 2)$ surface is the most common observed reconstruction on rutile $\mathrm{TiO}_{2}(110)$, which is caused by annealing of a reduced $\mathrm{TiO}_{2}(110)$ at high temperature $(748-998 \mathrm{~K})^{[12]}$. The structure of $(1 \times 2)$ (Figure 1.4) can be described as alternate BBO rows are absent from the regular $(1 \times 1)$ surface. We kept the annealing temperature below $950 \mathrm{~K}$ to avoid the the reconstruction from $(1 \times 1)$ to $(1 \times 2)$ and the $(1 \times 1)$ structure is testified by LEED in our experiments. 

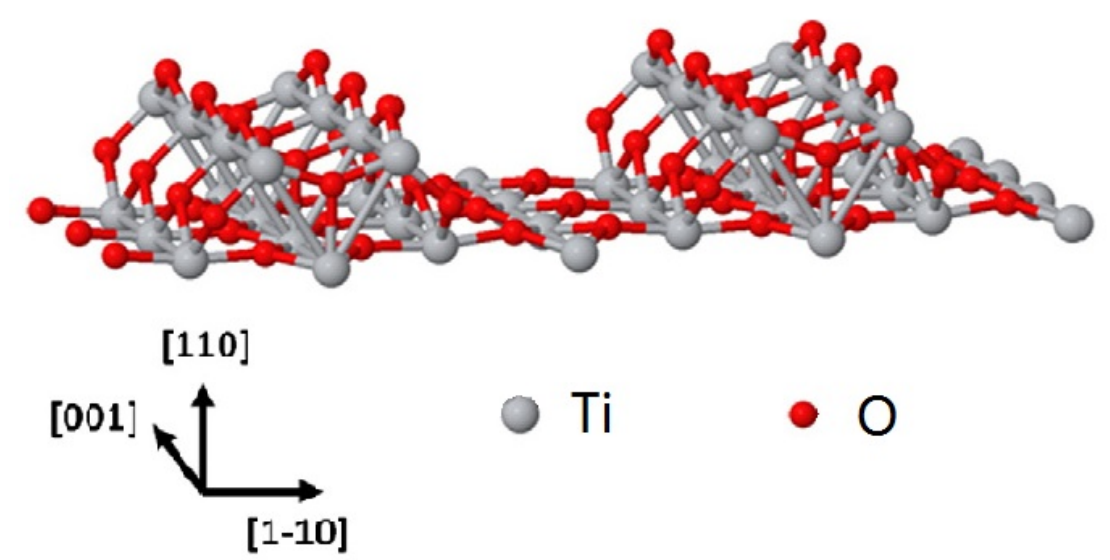

Figure 1.4: Ball-and-stick model of rutile $\mathrm{TiO}_{2}(110)-(1 \times 2)$. Figure is modified from Reference ${ }^{[13]}$.

\subsection{Previous Study of Water and Hydrogen Adsorbed on $\mathrm{TiO}_{2}(110)$}

\subsubsection{Water on $\mathrm{TiO}_{2}(110)$}

Water is probably considered the most important adsorbate on $\mathrm{TiO}_{2}$ and is widely studied, since water is present in virtually all $\mathrm{TiO}_{2}$ technological applications. Specifically on $\mathrm{TiO}_{2}(110)$, it is well established that adsorbed $\mathrm{H}_{2} \mathrm{O}$ dissociates at BBOV sites and forms one $\mathrm{OH}$ (called $\mathrm{BBOH}$ ) species at the vacancy site, and another $\mathrm{H}$ atom sits on a nearby $\mathrm{BBO}$, forming another $\mathrm{BBOH}$, as shown in Figure 1.5. Low temperature $\mathrm{STM}^{[14]}$ and high-resolution electron energy loss spectroscopy (HREELS) ${ }^{[15]}$ studies indicated that the dissociation of water can occur as low as $\sim 187 \mathrm{~K}$. Two BBOHs recombine when heated to $\sim 490 \mathrm{~K}$, forming a $\mathrm{H}_{2} \mathrm{O}$ (g) molecule and regenerating a BBOV site ${ }^{[16-17]}$. The oxygen isotope exchange experiments showed that BBOHs can 
diffuse to other BBO sites ${ }^{[16]}$. A typical TPD spectrum of $\mathrm{H}_{2} \mathrm{O}$ on $\mathrm{TiO}_{2}(110)$ is shown in Figure $1.6^{[18]}$, in which the three peaks, $163 \mathrm{~K}, 265 \mathrm{~K}$, and $490 \mathrm{~K}$, are attributed to multilayer water desorption, $\mathrm{H}_{2} \mathrm{O}$ desorption from $\mathrm{Ti}_{5 \mathrm{c}}$, and recombination of two $\mathrm{BBOH}$ species, respectively. The product of water dissociative adsorption, $\mathrm{BBOH}$, plays an important role in many aspects of catalysis on $\mathrm{TiO}_{2}$, including facilitating the adsorption of $\mathrm{O}_{2}$ on $\mathrm{TiO}_{2}(110)^{[19]}$, the exothermic reaction of $\mathrm{CO}_{2}$ and $\mathrm{H}_{2} \mathrm{O}$ to form bicarbonate species ${ }^{[20]}$ and the binding of $\mathrm{NO}$ on $\mathrm{TiO}_{2}(110)^{[21]}$. Therefore, researchers are interested in its diffusion properties. STM studies of $\mathrm{BBOH}$ species elucidated that $\mathrm{BBOH}$ pairs diffuse along the [1]10] direction through proton exchange with $\mathrm{H}_{2} \mathrm{O}^{[14]}$ and hop along the [001] direction ${ }^{[22]}$. It was also found that the two BBOHs, resulting from one $\mathrm{H}_{2} \mathrm{O}$ molecule dissociation at one BBOV site, are not equivalent by STM studies ${ }^{[22]}$. Besides monolayer water, multilayer water on $\mathrm{TiO}_{2}(110)$ also attracts researchers' interest. The first layer of $\mathrm{H}_{2} \mathrm{O}$, corresponding to the $\sim 265 \mathrm{~K}$ peak, is absorbed on $\mathrm{Ti}_{5 \mathrm{c}}$ sites with $\mathrm{O}$ atom pointing to $\mathrm{Ti}_{5 \mathrm{c}}$. This model was confirmed by a work function study ${ }^{[23]}$ and STM images $^{[14,24-26]}$. After water molecules fill the $\mathrm{Ti}_{5 c}$ sites, a second layer (or more layers) of water adsorbs over BBO rows, corresponding to the $175 \mathrm{~K}(\sim 163 \mathrm{~K})$ TPD peak. Structures of multilayer water are debated. A work function study suggested that the second layer water sits parallel to the surface ${ }^{[23]}$. HREELS results showed that hydrogen bond exists within the second layer, not between the first and second layers ${ }^{[27]}$. 
Nevertheless, H-D exchange experiments showed the second layer of water hydrogen bonds to the first layer ${ }^{[28]}$. Recently, Lee et al. found that water molecules can form H-bonded one-dimensional chains at high water coverage on $\mathrm{TiO}_{2}(110)$, through STM measurements and DFT calculations, which provided insight into nature of H-bonding in wetting of $\mathrm{TiO}_{2}{ }^{[29]}$.

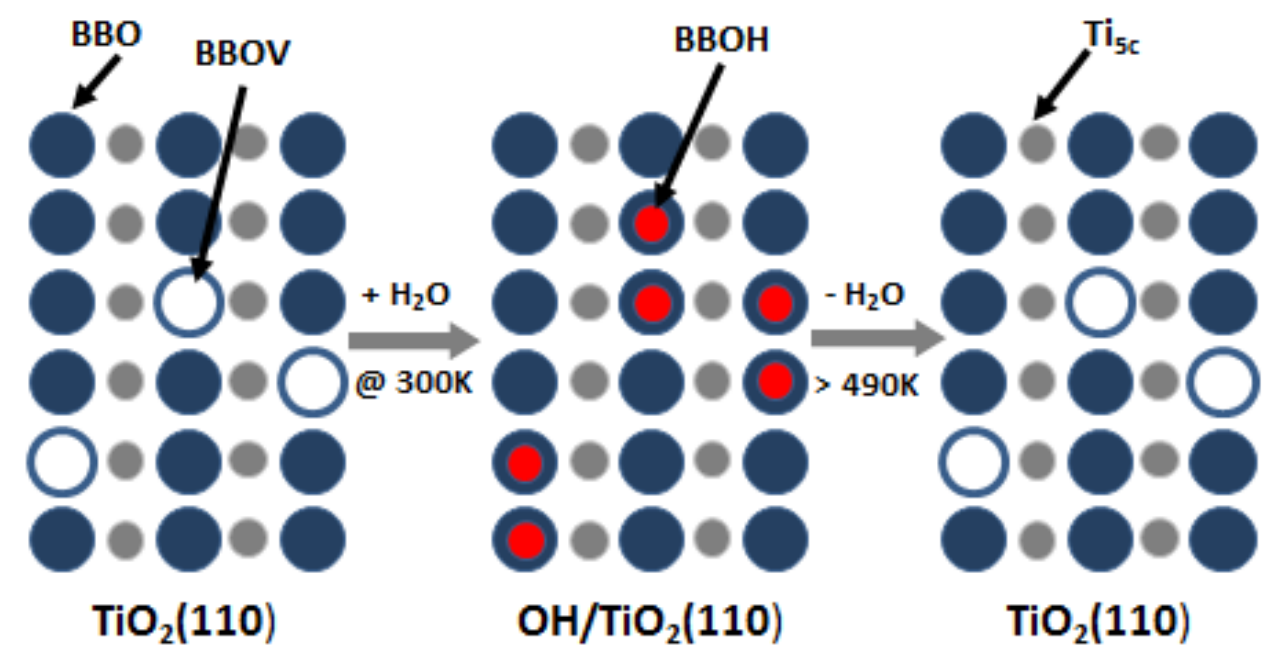

Figure 1.5: Schematic diagram of dissociative adsorption of $\mathrm{H}_{2} \mathrm{O}$ on $\mathrm{BBOV}$ sites and recombination of two $\mathrm{BBOHs}$ forming $\mathrm{H}_{2} \mathrm{O}$ and a $\mathrm{BBOV}$. 


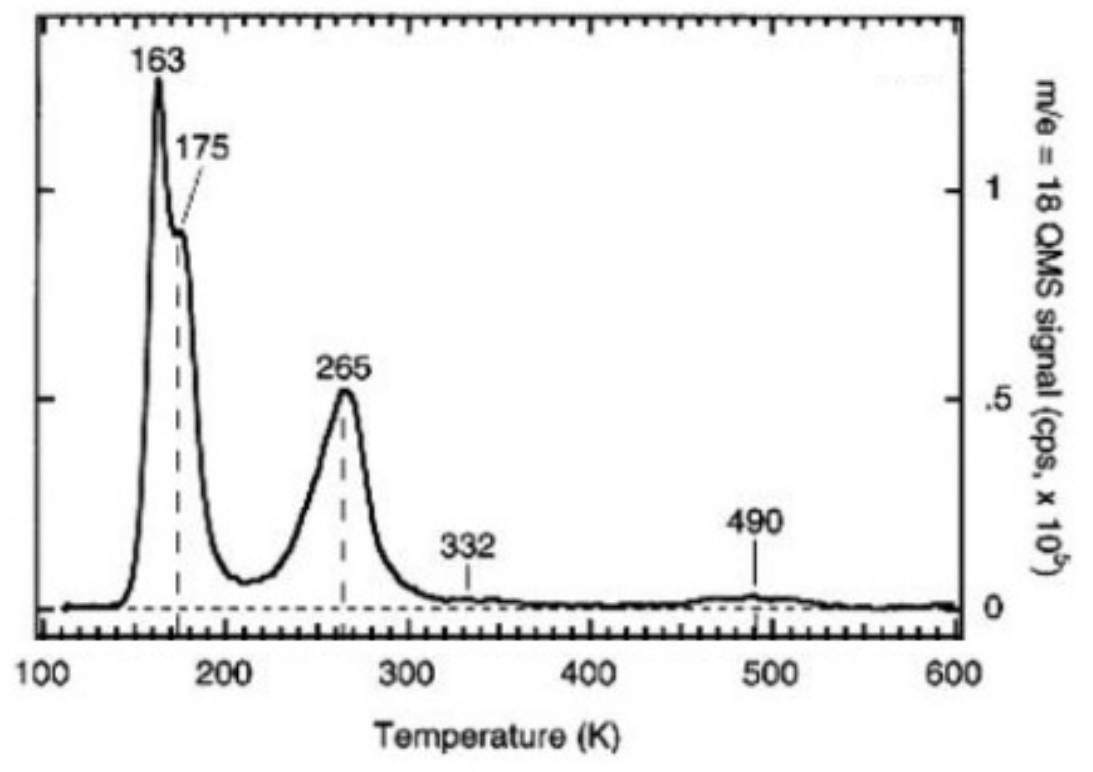

Figure 1.6: TPD spectra from a multilayer water adsorbed on $\mathrm{TiO}_{2}(110)$ at $110-118 \mathrm{~K}$ (heating rate $2 \mathrm{~K} \mathrm{~s}^{-1}$ ). Figure is partially reproduced from Reference ${ }^{[18]}$.

\subsubsection{Hydrogen on $\mathrm{TiO}_{2}(110)$}

Hydrogen is directly related to energy issues and it is also one of the most common species in surface science research. Unlike $\mathrm{H}_{2} \mathrm{O}$ on $\mathrm{TiO}_{2}(110)$, most of the behavior of molecular and atomic hydrogen on $\mathrm{TiO}_{2}(110)$ is still vague. $\mathrm{H}_{2}$ has a low sticking coefficient for $\mathrm{TiO}_{2}(110)^{[9,30]}$. On the contrary, atomic hydrogen can stick to $\mathrm{TiO}_{2}(110)$ at room temperature ${ }^{[30]}$. However, where adsorbed $\mathrm{H}$ atoms are located is still blurred. Unterberger et al. indicated that $\mathrm{TiO}_{2}(110)$ exposure to atomic $\mathrm{H}$ at $140 \mathrm{~K}$ produced hydroxyls ${ }^{[31]}$. Experimental and theoretical studies of a $(1 \times 1)$ adlayer of atomic $\mathrm{H}$ on $\mathrm{TiO}_{2}(110)$ by Wöll et al. indicated that $\mathrm{H}$ migrates into the bulk upon heating, in good 
agreement with the previous results of an IR study by Yates et al. ${ }^{[32]}$, instead of desorbing as $\mathrm{H}_{2} \mathrm{O}$ or $\mathrm{H}_{2}{ }^{[33]}$. Nonetheless, Du et al. found $\mathrm{H}$ atoms produced by trimethyl acetic acid dissociative adsorption and subsequent photolysis are bound to $\mathrm{BBO}$, and above $300 \mathrm{~K}$, the BBOHs will recombine to form $\mathrm{H}_{2} \mathrm{O}$, excluding the $\mathrm{H}$ diffusion into the bulk ${ }^{[34]}$. In addition, Iwasawa et al. showed that atomic $\mathrm{H}$ on $\mathrm{TiO}_{2}(110)$ exists in two forms, $\mathrm{Ti}-\mathrm{H}$ and Ti-OH, by their STM and ESD studies ${ }^{[35]}$.

\subsection{Previous Electron Stimulated Desorption Study of $\mathrm{TiO}_{2}(110)$}

Electron Stimulated Desorption (ESD) is a high-sensitivity tool to study $\mathrm{TiO}_{2}(110)$, though the reference of literatures that contain both ESD and $\mathrm{TiO}_{2}(110)$ is limited. The purposed of early researches of $\mathrm{ESD}$ on $\mathrm{TiO}_{2}(110)$ were to study some basic issues, such as identification of ions ${ }^{[36-39]}$, thermal stability of ESD of $\mathrm{O}^{+}$ions ${ }^{[40]}$, influence of surface reduction on adsorption of gases ${ }^{[41-42]}$, metallic surface layers ${ }^{[43-44]}$, and orientation of adsorbed species ${ }^{[45]}$. From 2000, researches of ESD on $\mathrm{TiO}_{2}(110)$ were more focused on the behavior of adsorbed small molecules on $\mathrm{TiO}_{2}(110)$. Madey et al. found different ESD behavior of $\mathrm{NH}_{3}$ preadsorbed on stoichiometric and oxygen deficient surfaces ${ }^{[46]}$. Kimmel et al. studied $<3$ monolayer (ML) water films on $\mathrm{TiO}_{2}(110)$ by ESD and found different products of desorption during irradiation ${ }^{[47]}$, and they further found multilayer water films can weaken the excitations in $\mathrm{TiO}_{2}$ and ESD of $\mathrm{H}$ from water on $\mathrm{Ti}_{5 c}{ }^{[48]}$. Their work of 
water on $\mathrm{TiO}_{2}(110)$ includes not only ESD but also electron-stimulated reaction. Recently, ESD studies of $\mathrm{O}_{2} / \mathrm{TiO}_{2}(110)$ showed efficient charge transfer from adsorbed oxygen species $\left(\mathrm{O}_{\mathrm{t}}\right.$, from $\mathrm{O}_{2}$ dissociated at $\left.\mathrm{Ti}_{5 \mathrm{c}}\right)$ to the $\mathrm{Ti}(3 \mathrm{~d})$ level accounts for a high $\mathrm{O}^{+} \mathrm{ESD}$ yield from $\mathrm{O}_{\mathrm{t}}$ compared to lattice oxygen ${ }^{[49]}$. Also, the band bending efficiency of charge transfer across $\mathrm{TiO}_{2}(110)$ were investigated by ESD of $\mathrm{O}_{2} / \mathrm{TiO}_{2}(110)$ and adding electron donor/accepter molecules to the surface ${ }^{[50]}$. Moreover, the kinetics of surface and bulk electron-hole pair recombination on $\mathrm{TiO}_{2}(110)$ was measured by using ESD of $\mathrm{O}_{2} / \mathrm{TiO}_{2}(110)$ as a probe ${ }^{[51]}$.

\subsection{Electron Stimulated Desorption Mechanisms}

Besides $\mathrm{TiO}_{2}$ (110), ESD has been widely used to study various metal and semiconductor surfaces, including $\mathrm{Pt}(111), \mathrm{Ni}(110), \mathrm{Ni}(111)$ and $\mathrm{Si}(110)^{[52]}$. Many mechanisms were proposed for ESD from surfaces, and they are reviewed in Reference ${ }^{[52-53]}$. In this section, two models will be mainly discussed, which are more closely related to the study of $\mathrm{TiO}_{2}(110)$ surface in this thesis.

\subsubsection{Menzel-Gomer-Redhead (MGR) Mechanism}

The Menzel-Gomer-Redhead model was proposed independently by Menzel and

Gomer in Chicago ${ }^{[54]}$ and Redhead in Ottawa in $1964^{[55]}$. The acronym MGR is applied to this model. It is one of the earliest and general models to explain ESD from surfaces. It 
incorporates adiabatic approximations and a semiclassical description of possible excitations to a surface-adsorbate system (Figure 1.7). It is a two-step mechanism. The first step is the ionization or excitation of an adsorbed atom or molecule by electron impact, which is similar to the Frank-Condon transition. An electron can be removed from one of the stable levels of an adsorbed species, resulting in a charged or excited adsorbate, whose interaction energy curve with the substrate may be very different from that of the neutral adsorbate. The second step is that the charged or excited adsorbate can either escape from the surface as an ion or excited neutral species (Figure 1.7a) or ground state neutral species (Figure 1.7b). In the first case, the system will relax by the excited adsorbate moving away from the surface, thus reducing the potential energy and imparting equivalent kinetic energy to the excited adsorbate. If no further processes intervene, the ion or excited neutral species will escape the surface into the vacuum with a kinetic energy range as shown in Figure 1.7a. The second case can be explained similarly in Figure 1.7b. The excited adsorbate is very close to the surface, so it has a finite probability of being reneutralized by an Auger or resonance neutralization process. The net result is that the excited adsorbate returns to the ground state but with some kinetic energy. If this kinetic energy is larger than the potential energy difference between that represented by the ground state curve at the point of de-excitation and the vacuum level, the adsorbate can escape from the surface as a neutral species. 


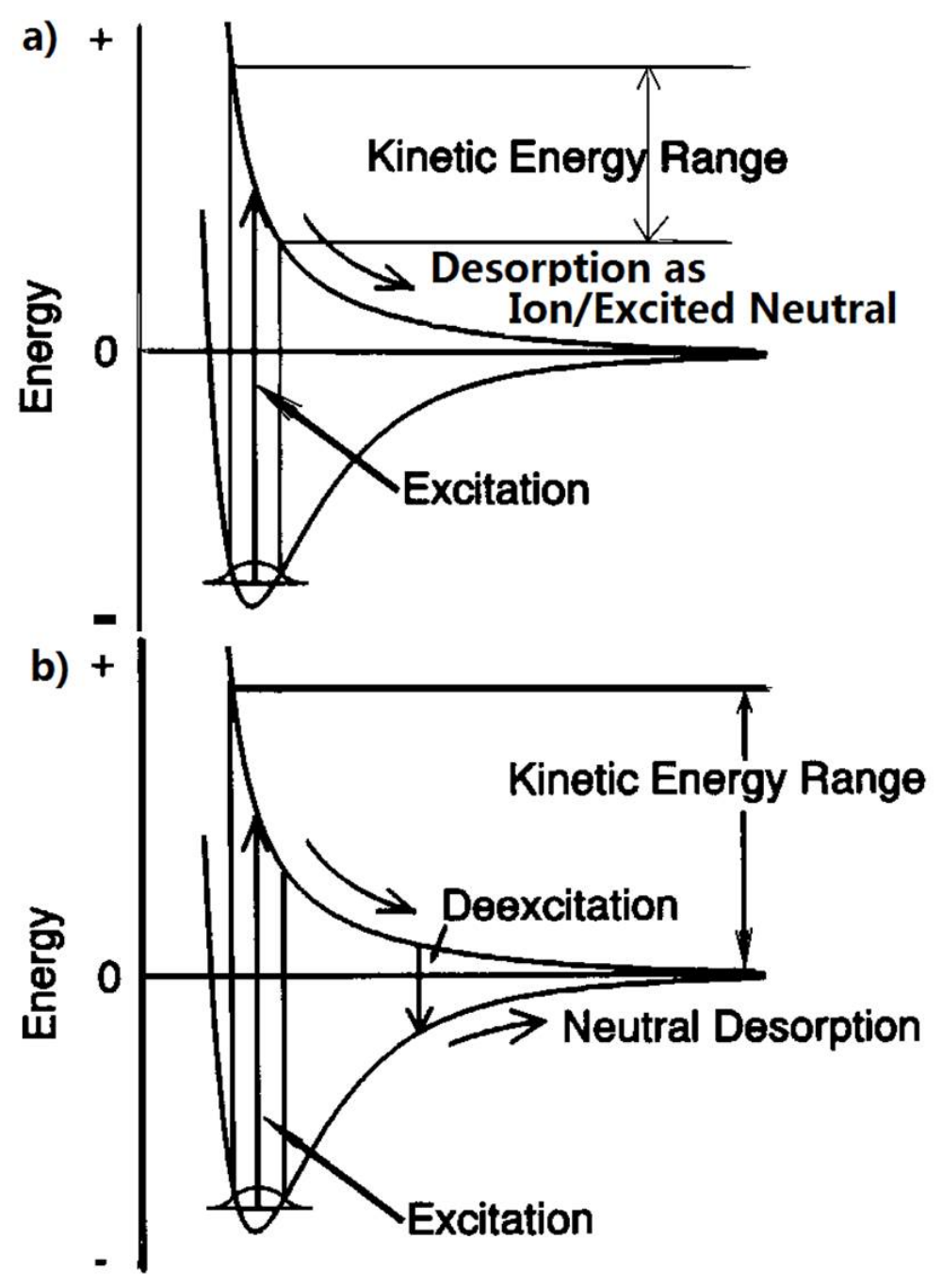

Figure 1.7: Schematic diagram showing the processes involved in the ESD of an adsorbate as (a) an ion or excited neutral species or (b) ground state neutral species, according to the MGR model.

\subsubsection{Knotek-Feibelman (K-F) Mechanism}

In 1978, Knotek and Feibelman (K-F) ${ }^{[56]}$ proposed a model for $\mathrm{O}^{+}$desorption from $\mathrm{TiO}_{2}$ and other highly ionic maximal valence oxides, such as $\mathrm{V}_{2} \mathrm{O}_{5}$ and $\mathrm{WO}_{3}$. This 
mechanism is based on the observation that the threshold energy for $\mathrm{O}^{+} \mathrm{ESD}$ from $\mathrm{TiO}_{2}$ corresponds to the excitation energy of $\mathrm{Ti}(3 \mathrm{p})$ core level $(34 \mathrm{eV})$. To rationalize the formation of an $\mathrm{O}^{+}$ion from an $\mathrm{O}^{2-}$ species, it was proposed that the $\mathrm{Ti}(3 \mathrm{p})$ core hole is filled with electrons from $\mathrm{O}(2 \mathrm{p})$ orbitals via an inter-atomic Auger process from a neighboring $\mathrm{O}^{2-}$. It was also argued that since no electron exists at the Ti(3d) level in the $\mathrm{Ti}^{4+}$, no intra-atomic Auger process from the Ti(3d) level to the Ti(3p) level will occur. If three electrons escape from the oxygen, the $\mathrm{O}^{2-}$ becomes $\mathrm{O}^{+}$. This $\mathrm{O}^{+}$ion can then be ejected from the surface by Coulomb repulsion from the surrounding $\mathrm{Ti}^{4+}$ ions in the lattice. 


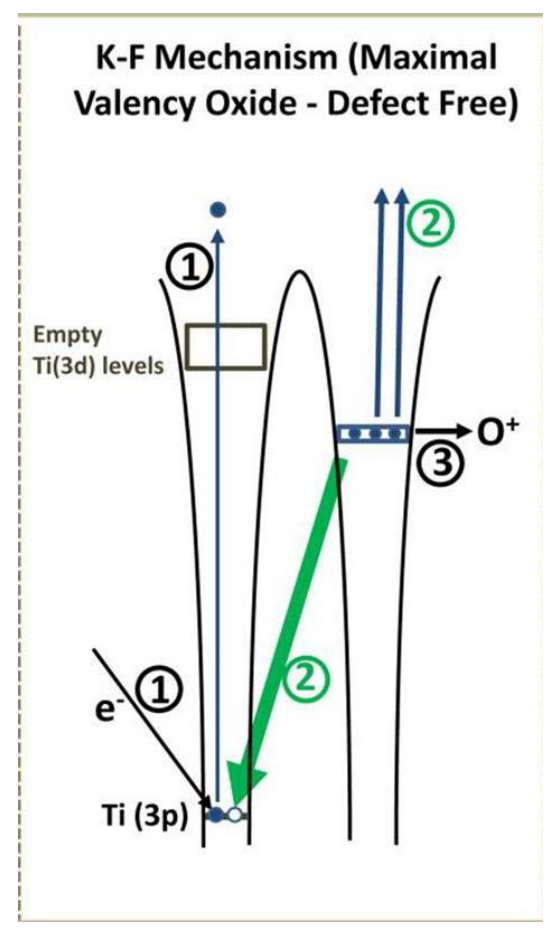

Figure 1.8: Schematic diagram of Knotek-Feibelman (K-F) mechanism for $\mathrm{O}^{+}$ESD from a TiO2 surface. Figure is reproduced from Reference ${ }^{[57]}$. 


\section{CHAPTER TWO: Instrumentation and Sample Details}

\subsection{Ultra-high Vacuum Apparatus}

The surface experiments presented in this thesis were conducted in a stainless steel ultrahigh vacuum (UHV) chamber equipped with several surface analysis techniques. This chamber operates at a base pressure of $<3 \times 10^{-11} \mathrm{mbar}$, which is measured by an ionization gauge located in the lower portion of the chamber. The ultrahigh vacuum is kept by a turbomolecular pump (Leybold-Heraeus), an ion pump (Leybold-Heraeus) and a titanium sublimation pump (Leybold-Heraeus).

\subsection{Instrumentation, Methods and Sample Details}

The UHV system is equipped with the following surface analysis tools in the upper portion (Figure 2.1): (1) a combined time-of-flight electron-stimulated desorption ion angular distribution (TOF-ESDIAD), (2) a pulse counting low energy electron diffraction (LEED), a cylindrical-mirror-analyzer-Auger electron spectrometer (CMA-AES, Perkin-Elmer), (3) a differentially pumped and shielded and apertured quadrupole mass spectrometer (QMS, UTI 100C) for temperature programmed desorption (TPD) measurements and photon stimulated desorption (PSD) measurements, (4) a ultraviolet (UV) source (500 W Hg arc lamp, Oriel), whose light is conducted by fiber optics into the 
vacuum, (5) an ion gun for $\mathrm{Ar}^{+}$sputter cleaning, and (6) a collimated and calibrated microcapillary array doser.

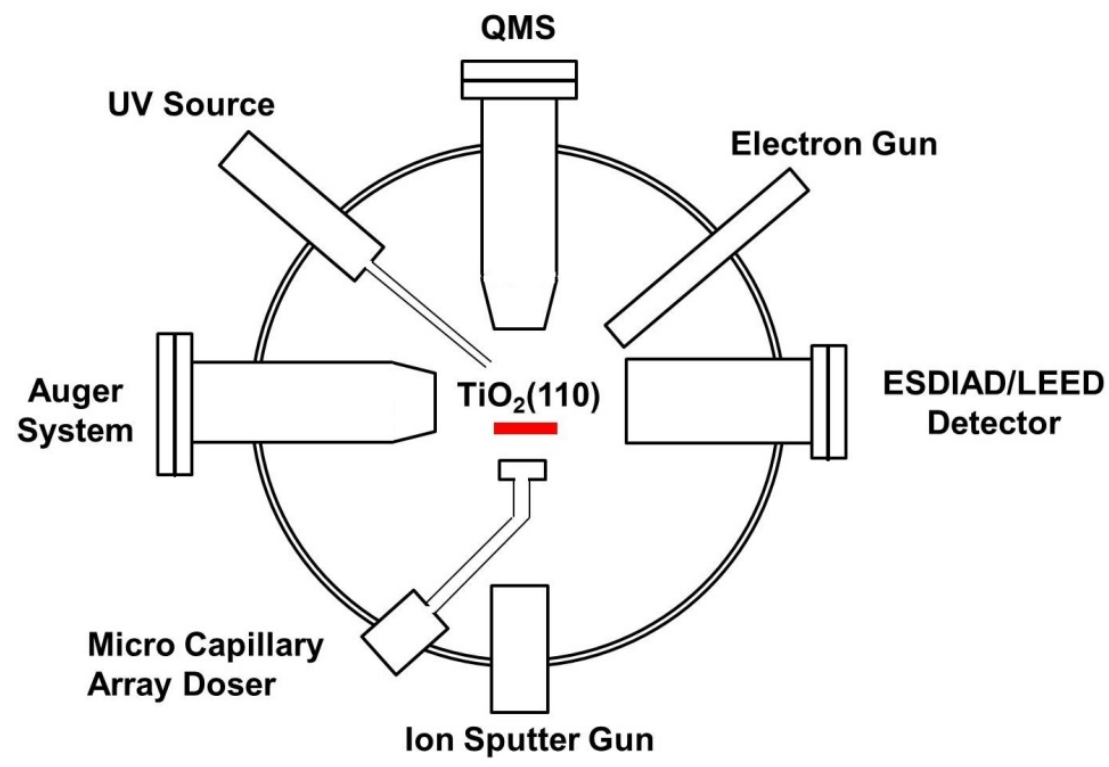

Figure 2.1: Top-down schematic diagram of the UHV chamber and surface science tools.

\subsubsection{Time-of-flight Electron Stimulated Desorption Ion Angular}

\section{Distribution}

The diagram of ESDIAD is shown in Figure 2.2. The incident pulsed electron beam with frequency of 2-40 kHz and width of $50 \mathrm{~ns}$, is obtained by an electron gun of $180 \mathrm{eV}$ and a square pulse generator (Avtech, AVR-E2-PS). Atoms or molecules on the surface can be excited by the electron beam and be ejected from the surface as ions (usually positive ions) or neutral species. We apply a positive voltage (+30 V) on the crystal to suppress the secondary electron emission. The first two hemispherical grids $\left(G_{1}\right.$ and $\left.G_{2}\right)$ are at ground 
potential, and the $\mathrm{G}_{4}$ is biased by $-1.2 \mathrm{kV}$, so that the emitted positive ions are guided to accelerate toward the microchannel plates (MCPs). $\mathrm{G}_{3}$ is biased by $+10 \mathrm{~V}$ to avoid low energy ions hitting the MCPs to reduce the noise. When an ion hits the first MCP, it produces an electron cascade. The electrons then hit the second MCP and produce more electron cascades. The electrons generated from the second MCP hit the resistive anode (RA), where signals are generated and imported into an analog position computer (Model 2401, Surface Science Laboratory), which subsequently calculates the coordinates (x, y) of the position of electron impact. The arriving time of ions are subsequently analyzed by a pico-timing discriminator (Ortec) and a time amplitude converter (Ortec). The time-of-flight ( $\mathrm{t}$ ) of a detected ion is determined by the difference between the electron pulse and the arriving time. The $\mathrm{x}, \mathrm{y}$ and $\mathrm{t}$ information is digitized by two Nuclear Data ADCs (ND 581) and a Fast Comtech ADC (Model 7070) and then transported to a computer, where the MPANT software (FAST ComTec) is used for data analysis and visualization. The major characteristics of this software used in this thesis are the time-of-flight spectra of ions and ion angular distribution patterns of peaks. 


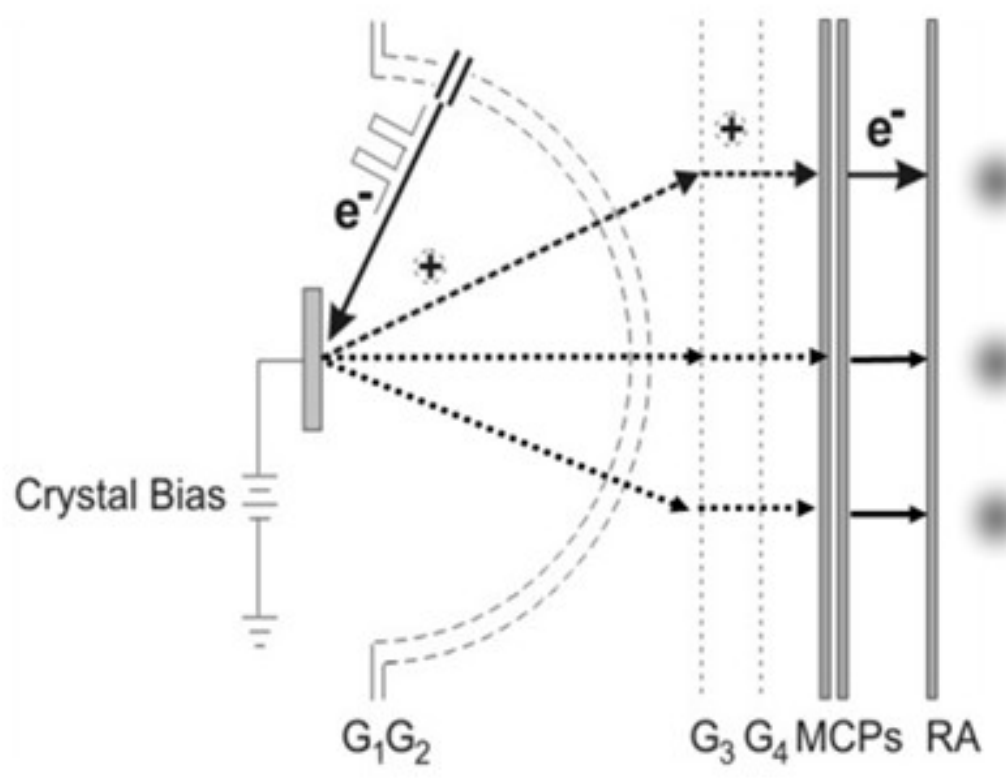

Figure 2.1: Diagram of ESDIAD.

\subsubsection{Low Energy Electron Diffraction}

In this thesis, low energy electron diffraction (LEED) is used as an auxiliary tool to assure that the single crystal $\mathrm{TiO}_{2}(110)$ is in a well-ordered $(1 \times 1)$ surface structure. The mechanism of LEED is described as follows: In LEED, monochromatic incident electrons (20-1000eV) which are elastically scattered back from a surface are analyzed; if the surface array is order, an ordered LEED pattern is achieved. The LEED mode can be fulfilled by changing the grid polarity and electron energies, and using continuous electron beams instead of pulsed electron beams, based on the settings of TOF-ESDIAD. Thus, LEED 
patterns are obtained from the MPANT software. Figure 2.3 shows a clear LEED pattern of our sample. The value of b/a (2.16) is close to $0.649 / 0.295(2.20)^{[9]}$, indicating that the surface is $(1 \times 1)$.

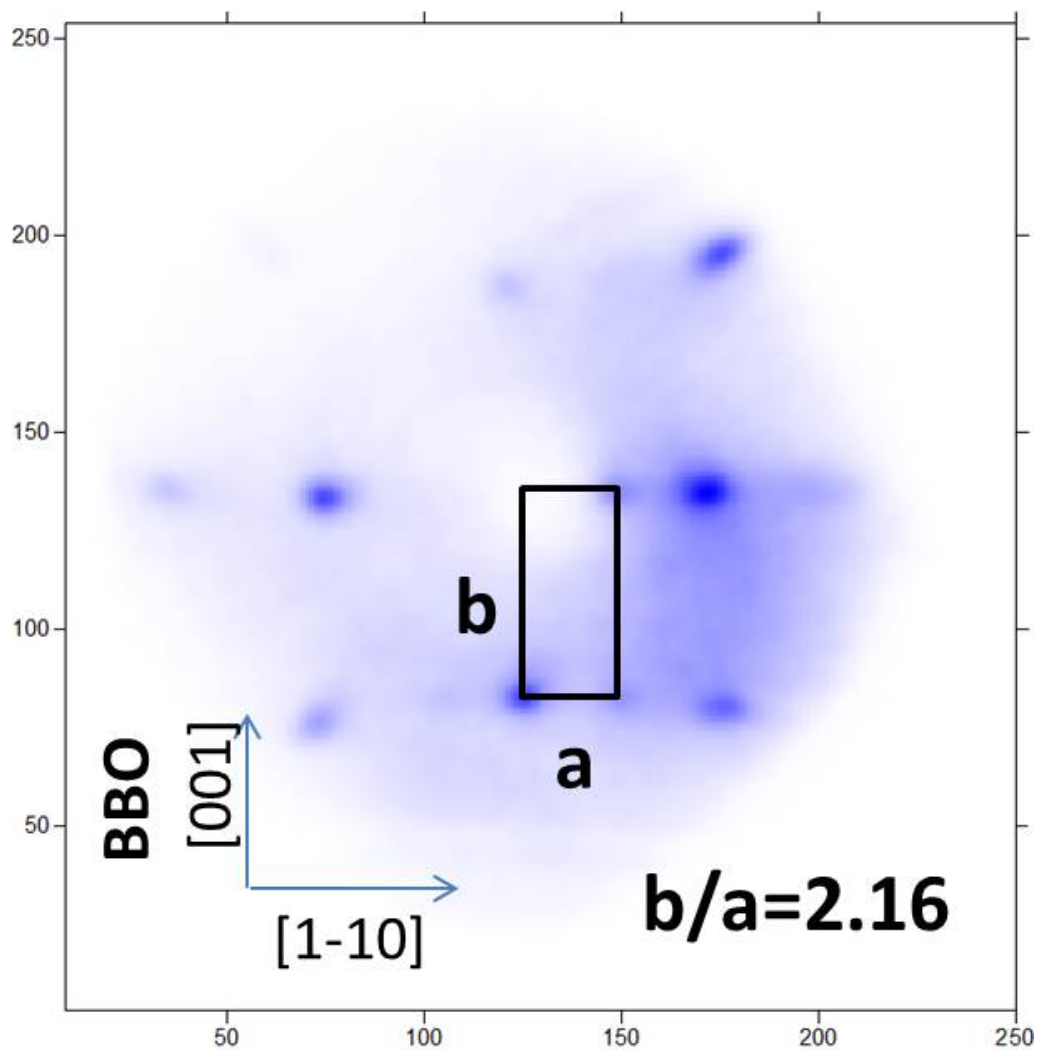

Figure 2.3: $\mathrm{LEED}$ pattern of $\mathrm{TiO}_{2}(110)$ used in this thesis showing its $(1 \times 1)$ order.

\subsubsection{Auger Electron Spectroscopy}

Auger electron spectroscopy (AES) is used as a supplementary tool to check the cleanliness of the $\mathrm{TiO}_{2}(110)$ surface, usually after the sample is exposed in air pressure and the UHV condition is rebuilt. Figure 2.4 illustrates the Auger effect. An incident high 
energy electron knocks out a core electron and leaves a hole. The hole will be filled by an electron transition from an upper level. The energy released in this transition is removed as a photon (X-ray fluorescence) or by a third electron from upper levels: Auger electrons will then escape into the vacuum with discrete kinetic energies. The Auger electrons are element specific (not applied to $\mathrm{H}$ and $\mathrm{He}$ ) and thus can be used to determine the chemical composition of the surface.

KLL - Auger transition

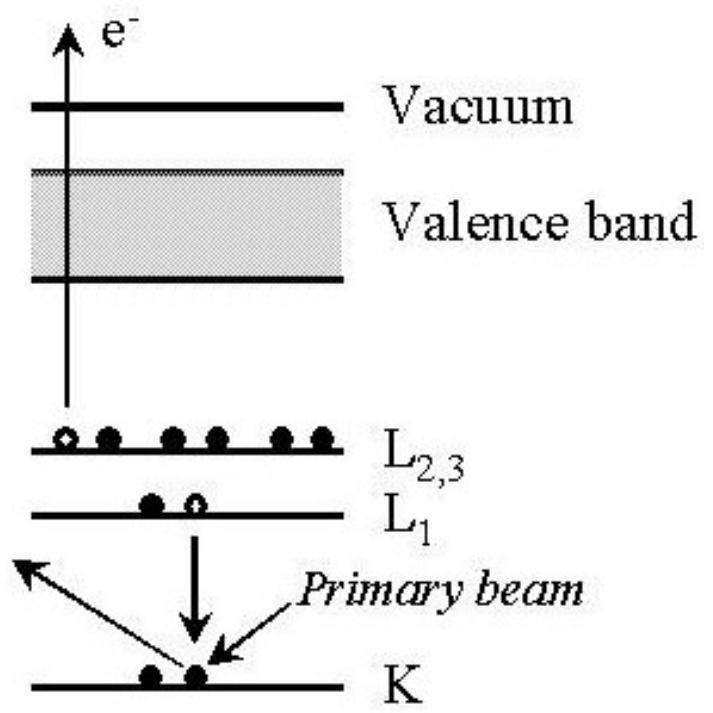

Figure 2.4: Schematic diagram of Auger process 


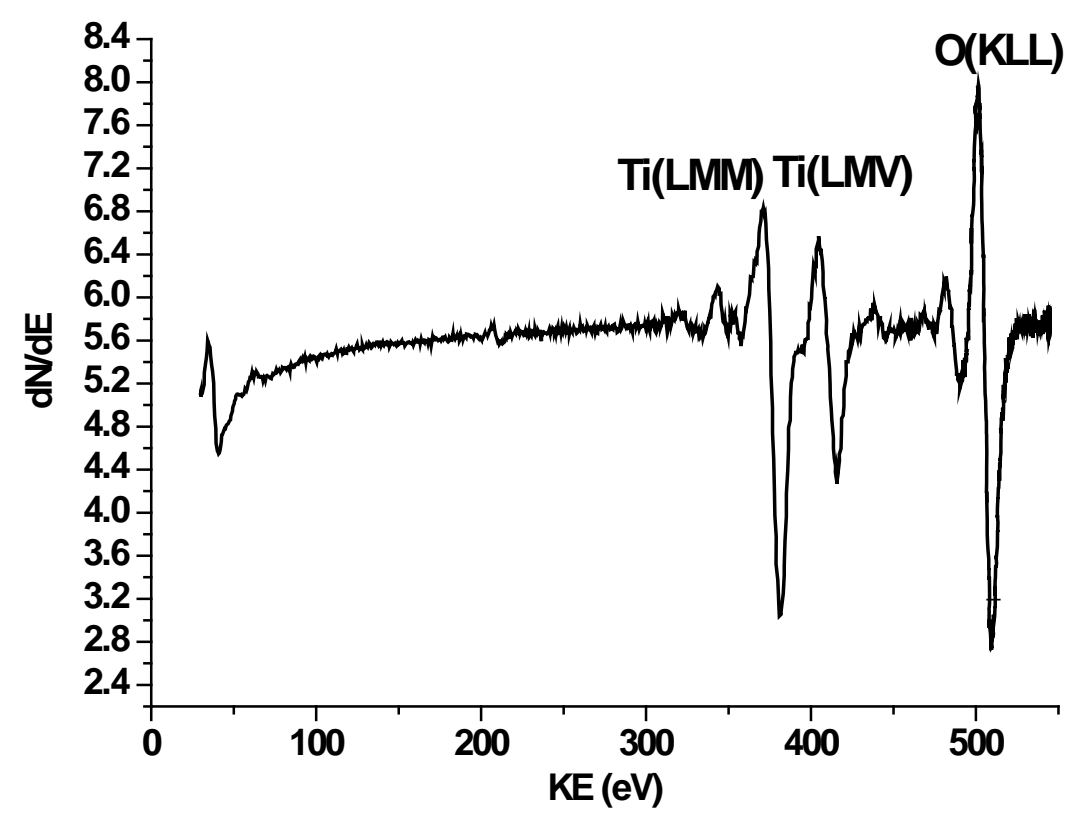

Figure 2.5: Auger electron spectrum of sputter-annealed $\mathrm{TiO}_{2}(110)$.

\subsubsection{Quadrupole Mass Spectrometer}

In our experiments, quadrupole mass spectrometer is mainly used for residual gas analysis, checking the impurity of gases, and monitoring the desorbed species in TPD and PSD experiments. (Figure 2.6) 


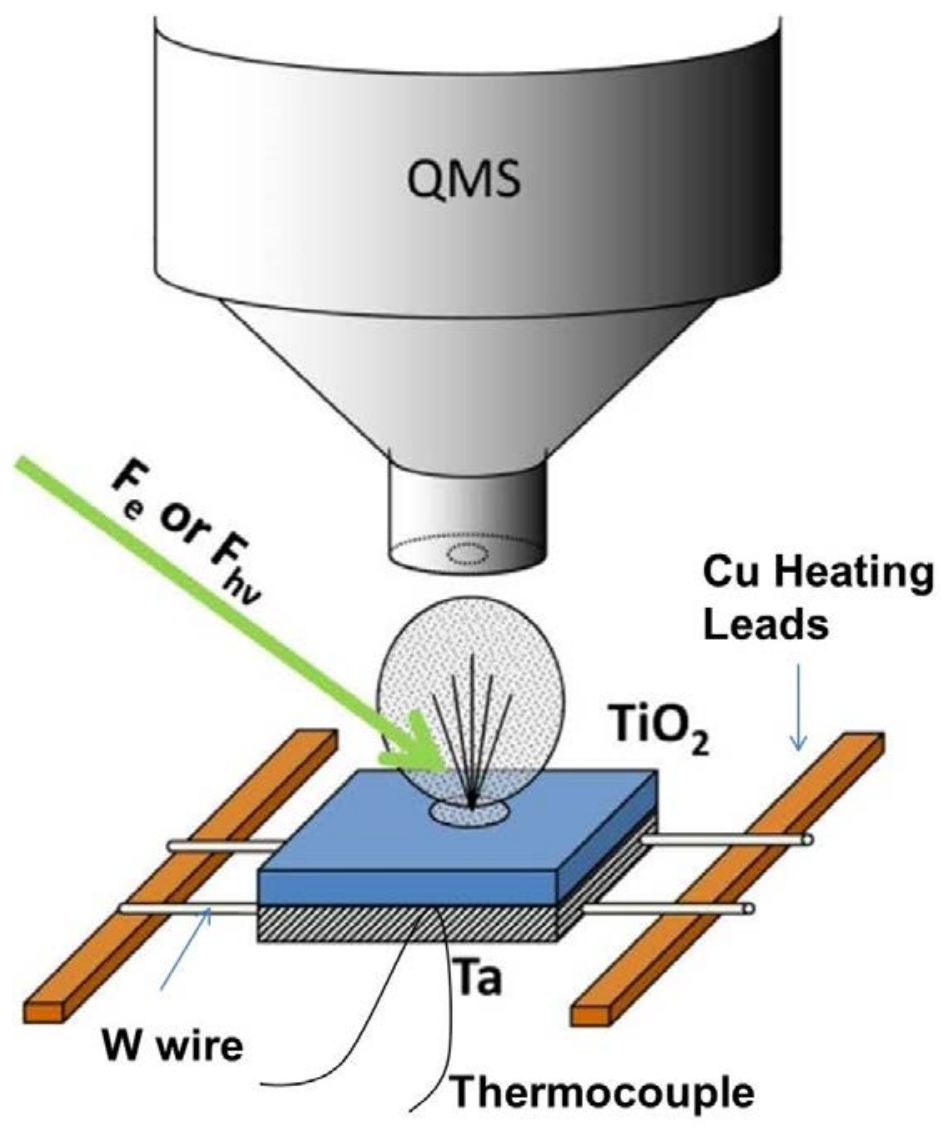

Figure 2.6: Diagram of TPD-QMS or PSD-QMS, and $\mathrm{TiO}_{2}(110)$ mount. The incident electron flux $\left(F_{e}\right)$ is $10^{10}-10^{14}$ electrons $\mathrm{cm}^{-2} \mathrm{~s}^{-1}$, and the incident photon flux $\left(F_{\text {hv }}\right)$ is $\sim 10^{14}$ photons $\mathrm{cm}^{-2} \mathrm{~s}^{-1}$.

\subsubsection{Temperature Programmed Desorption}

In temperature programmed desorption, a constant temperature ramp (dT/dt) is applied to the sample and the QMS is used to monitor the species desorbed from the surface. Both the control of temperature and monitor of QMS signals are operated through the software LabVIEW. 


\subsubsection{Photon Stimulated Desorption}

In photon stimulated desorption, the UV light is applied to the sample and QMS is used to monitor the species desorbed from the surface. The UV source (500 W Hg arc lamp, Oriel) generates photons of energies ranging from near-IR to UV (Figure 2.7). A 10-cm long IR filter filled with water is used to screen the portion of IR. Besides, longpass filters (Andover, Edmund) and bandpass filters (Newport, Andover) are used to achieve UV photons of desired energies. The filtered UV light is conducted by the fiber optics into the vacuum. The fiber material used in both feedthrough and cable is pure $600 \mu \mathrm{m}$ silica core with a doped silica cladding.

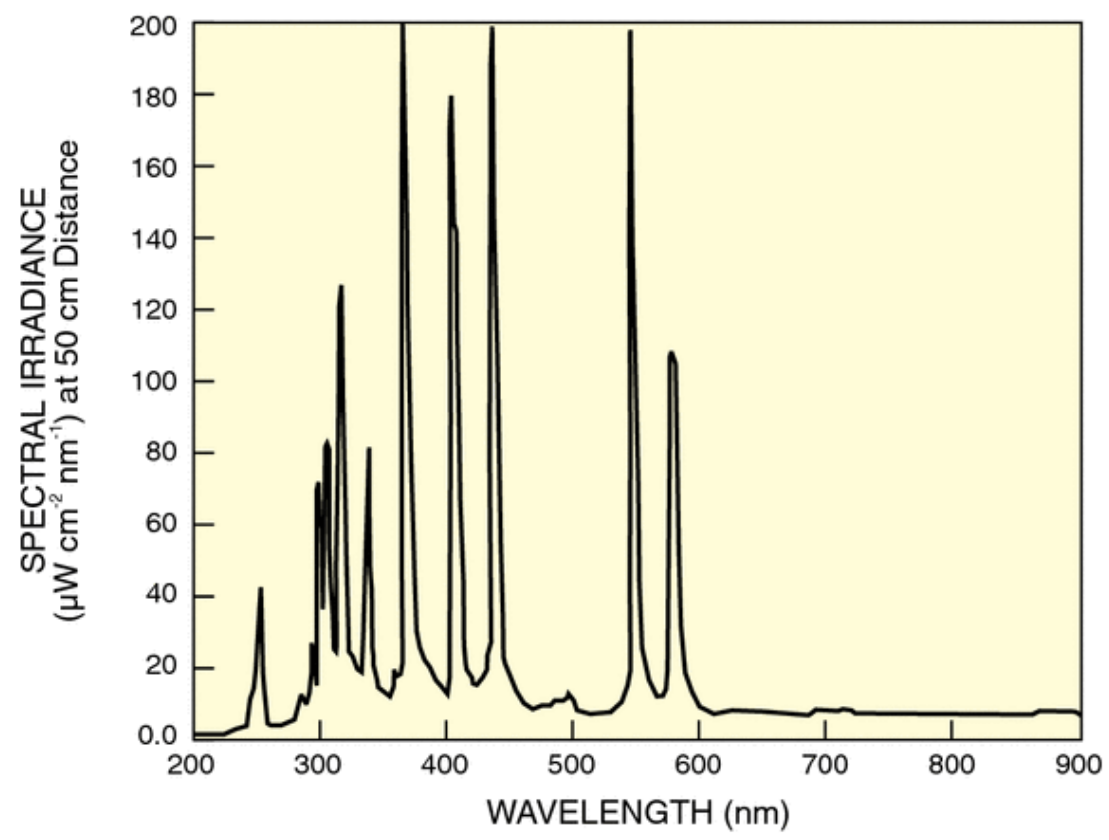

Figure 2.7: Spectrum of typical output of a $500 \mathrm{~W} \mathrm{Hg} \operatorname{arc~lamp}^{[58]}$. 


\section{3 $\mathrm{TiO}_{2}$ Sample Mounting, Cleaning and Preparation}

The polished rutile $\mathrm{TiO}_{2}(110)$ single crystal (Princeton Scientific, $7 \times 7 \times 1 \mathrm{~mm}^{3}$ ) is cemented (using AREMCO 571 cement) onto a Ta support plate to facilitate thermal contact (Figure 2.6). No part of the Ta plate is exposed in the forward direction, and only the crystal is seen in measurements and microcapillary array dosing ${ }^{[59]}$. Two tungsten wires are spot-welded onto the back of the Ta plate for resistive heating. The temperature of the crystal is measured and electronically controlled by a type-K thermocouple (chromel-alumel) cemented (AREMCO 571 cement) to the back center of the crystal through a hole in the Ta plate. The crystal is cleaned by $\mathrm{Ar}^{+}$sputtering (1000 eV, $45 \mathrm{~min}$ ) followed by annealing ( $950 \mathrm{~K}, 10 \mathrm{~min}$ ) before experiments.

\subsection{Gas Handling and Dosing}

In this thesis, two methods are employed to expose gas to the surface or into the chamber: background dosing and microcapillary array dosing. Background dosing is used commonly in checking the impurity of gases. Besides, in Chapter 4, dosing atomic $\mathrm{H}$ onto the surface is achieved by pyrolysis of $\mathrm{H}_{2}$ backfilled into the vacuum. In most other cases, gases are dosed to the surface through a microcapillary beam doser. This doser is calibrated by ${ }^{16} \mathrm{O}_{2}$ and the flux is $\mathrm{F}_{\mathrm{O}_{2}}=1.67 \times 10^{12}$ molecules torr ${ }^{-1} \mathrm{~s}^{-1}$ (measurement made by Zhen Zhang). The flux of another gas $\mathrm{A}$ is calculated by $\mathrm{F}_{\mathrm{A}}=\mathrm{F}_{\mathrm{O}_{2}}\left(M_{\mathrm{O}_{2}} / M_{\mathrm{A}}\right)^{1 / 2}$, where $\mathrm{M}=$ gas 
molecular weight. 


\section{CHAPTER THREE: Defect-Electron Spreading on the $\mathrm{TiO}_{2}(110)$ Semiconductor Surface by Water Adsorption $^{[57]}$}

\subsection{Abstract}

The dissociative adsorption of water at oxygen-vacancy defect sites on the $\mathrm{TiO}_{2}(110)$ surface spatially redistributes the defect electron density originally present at subsurface sites near the defect sites. This redistribution of defect-electrons makes them more accessible to $\mathrm{Ti}^{4+}$ ions surrounding the defects. The redistribution of electron density decreases the $\mathrm{O}^{+}$desorption yield from surface lattice $\mathrm{O}^{2-}$ ions in $\mathrm{TiO}_{2}$, as excited by electron stimulated desorption (ESD). A model in which $\mathrm{OH}$ formation on defect sites redistributes defect electrons to neighboring $\mathrm{Ti}^{4+}$ sites is proposed. This switches off the Knotek-Feibelman mechanism for ESD of $\mathrm{O}^{+}$ions from lattice sites. Conversely, enhanced $\mathrm{O}^{+}$reneutralization could also be induced by redistribution of defect electrons. The redistribution of surface electrons by adsorption is further verified by the use of donor and acceptor molecules which add or remove electron density.

\subsection{Introduction}

The $\mathrm{TiO}_{2}(110)$ surface is a widely-used model oxide surface for thermally-activated 
catalysis as well as for photocatalysis and photovoltaic processes induced by UV light ${ }^{[8-9,}$ 60-61]. Water has been thoroughly investigated as an adsorbate on $\mathrm{TiO}_{2}(110)$ and the practical conversion of water to hydrogen and oxygen on $\mathrm{TiO}_{2}$ surfaces using solar energy is a promising goal, building on the early pioneering work of Honda and Fujishima ${ }^{[1]}$. Bridge-bonded oxygen vacancy (BBOV) sites on the surface, formally associated with two defect electrons in their vicinity, play an important role in determining the surface reactivity of $\mathrm{TiO}_{2}(110)^{[9,62]}$. Water molecules dissociate at $\mathrm{BBOV}$ sites producing an $-\mathrm{OH}$ group (called $\mathrm{BBOH}$ ) at the vacancy and also a second $-\mathrm{OH}$ group at a nearby $\mathrm{BBO}$ site (see inset in Figure 3.1 $)^{[14,22,63]}$. Heating to $\sim 490 \mathrm{~K}$ causes two BBOH groups to recombine, producing $\mathrm{H}_{2} \mathrm{O}(\mathrm{g})$ and regenerating a BBOV site ${ }^{[17]}$.

An electronic state with energy $\sim 0.8 \mathrm{eV}$ below the Fermi level on $\mathrm{TiO}_{2}(110)$, which participates in the chemical bonding of adsorbed molecules, is fully or partially associated with the defect electrons on BBOV sites ${ }^{[64-67]}$. This defect electronic state is hardly influenced in energy or intensity by water dissociation on the defect sites, as demonstrated by both photoemission spectroscopy ${ }^{[64,68]}$ and electron energy loss spectroscopy ${ }^{[15]}$. Furthermore no additional electronic states in the bandgap region are produced by $\mathrm{BBOH}$ adsorption on defect sites. The filling of the BBOV sites by $\mathrm{BBOH}$ formation does not influence the $\mathrm{TiO}_{2}$ surface reactivity toward $\mathrm{O}_{2}{ }^{[69]}$. The above observations raise an interesting question about the spatial distribution of the defect-electrons associated with 
the defect sites before/after the dissociative adsorption of $\mathrm{H}_{2} \mathrm{O}$ at these sites. This question has been explored by experiments and by theoretical calculations ${ }^{[70-72]}$. The presence of $\mathrm{Ti}^{3+}$ on the defective $\mathrm{TiO}_{2}$ surface as seen by experimental measurements ${ }^{[15,68,73-75]}$ indicates that the defect-electrons are localized on nearby Ti atoms, formally reducing $\mathrm{Ti}^{4+}$ to $\mathrm{Ti}^{3+}$. Using the resonant photoelectron diffraction (PED) method, Krüger et al. ${ }^{[65,74]}$ found that most defect charge is distributed on the subsurface Ti atoms, especially on the second layer $\mathrm{Ti}$ atoms. Recent theoretical results ${ }^{[76-79]}$ also proposed that the defect-electron on defective $\mathrm{TiO}_{2}$ surface is localized on one $\mathrm{Ti}$ atom and induces a local lattice distortion forming a polaron. The mobile polarons with low activation energy for motion in the surface and subsurface region make the defect-electrons appear to be delocalized near the surface. ${ }^{[79-80]}$ The influence of the dissociative adsorption of $\mathrm{H}_{2} \mathrm{O}$ on defect sites on the spatial distribution of defect-electrons is still an open question. Combining STM and DFT calculations, Minato et al. ${ }^{[81]}$ found that the defect-electrons at both $\mathrm{BBOV}$ and $\mathrm{BBOH}$ sites appear to be delocalized along the surface. Di Valentine et al. ${ }^{[72,82]}$ found that the defect site and the BBOH site both involve a spatially-localized electronic state; in contrast, Liu et al. ${ }^{[19]}$ theoretically observed delocalization of the electronic state when $\mathrm{BBOH}$ was produced at the BBOV defect sites.

Our experiment to be described below suggests that the defect electrons are spread out spatially by $\mathrm{OH}$ formation near BBOV sites. This could be due to actual delocalization 
of electron wavefunctions or their redistribution to other Ti sites. From the experiment it is impossible to separate these two concepts relating to spreading of defect electrons by $\mathrm{H}_{2} \mathrm{O}$ dissociative adsorption.

\subsection{Experimental Section}

The experiment was carried out in a stainless steel UHV chamber (base pressure below $3 \times 10^{-11}$ mbar) equipped with a combined time-of-flight electron stimulated desorption ion angular distribution (TOF-ESDIAD) and pulse counting low energy electron diffraction (LEED) apparatus, a cylindrical-mirror-analyzer-Auger electron spectrometer (CMA-AES), and an apertured quadrupole mass spectrometer (QMS). A $\mathrm{TiO}_{2}(110)-(1 \times 1)$ crystal (Princeton Scientific, $7 \times 7 \times 1 \mathrm{~mm}^{3}$ ) with BBOV density of $10 \%$ $\mathrm{BBO}$ sites on the surface was prepared by cycles of $\mathrm{Ar}^{+}$sputtering and annealing in UHV at $950 \mathrm{~K}$. The cleanliness and surface structure of the $\mathrm{TiO}_{2}(110)-(1 \times 1)$ surface was confirmed by AES and LEED, respectively. A partially-hydroxylated $\mathrm{TiO}_{2}(110)$ surface was then prepared by exposing to water vapor at $300 \mathrm{~K}$ from a calibrated and collimated molecular beam source. The complete dissociation of water on BBOV sites occurs and intact water molecules are not present on the surface at the low coverage and adsorption temperature employed. The ESD experiments on the $\mathrm{TiO}_{2}(110)$ surface employed pulsed $180 \mathrm{eV}$ electrons at $40 \mathrm{kHz}$ with $75 \mathrm{~ns}$ width, and the produced positive ions are separated by their

time-of-flight caused by the ion mass difference ${ }^{[83]}$. A $+30 \mathrm{~V}$ or $+40 \mathrm{~V}$ bias was applied to 
the sample during the ESDIAD measurements of the angular distribution of desorbing ions. Adsorption of gases, such as ${ }^{15} \mathrm{~N}^{18} \mathrm{O},{ }^{18} \mathrm{O}_{2}, \mathrm{ND}_{3}$, and $\mathrm{C}_{5} \mathrm{D}_{5} \mathrm{~N}$ from the calibrated beam was also carried out. The temperature-programmed desorption (TPD) of $\mathrm{H}_{2} \mathrm{O}$ molecules used a heating rate of $2 \mathrm{~K} \mathrm{~s}^{-1}$ and desorbing products were detected by the line-of-sight QMS.

\subsection{Results and Discussion}

Figure 3.1 shows the time-of-flight distribution of $\mathrm{H}^{+}$and $\mathrm{O}^{+}$ions produced by ESD on the $\mathrm{TiO}_{2}(110)$ surface. On the clean $\mathrm{TiO}_{2}(110)$ surface containing $10 \% \mathrm{BBOV}$ sites (curve a), $\mathrm{O}^{+}$ions originating from $\mathrm{BBO}$ surface lattice $\mathrm{O}^{2-}$ sites were observed at a flight time of $2.2 \mu$ s. A trace amount of $\mathrm{H}^{+}$from $\mathrm{BBOH}$ due to the dissociation of residual $\mathrm{H}_{2} \mathrm{O}$ (in UHV) on the BBOV sites was also observed at a flight time of $0.5 \mu$ s. After exposing the $\mathrm{TiO}_{2}(110)$ surface to $7.2 \times 10^{13} \mathrm{H}_{2} \mathrm{O}$ molecules $\mathrm{cm}^{-2}$ at $300 \mathrm{~K}$, water molecules were dissociated at the surface, filling the BBOV sites, and each $\mathrm{H}_{2} \mathrm{O}$ molecule formed two $\mathrm{BBOH}$ species (upper inset in Figure 3.1). On the hydroxylated $\mathrm{TiO}_{2}(110)$ surface (curve b), a huge yield of $\mathrm{H}^{+}$from $\mathrm{BBOH}$ species was observed. Most notably however, the $\mathrm{O}^{+}$ signal decreased significantly upon adding a small coverage of $\mathrm{H}_{2} \mathrm{O}$ undergoing dissociative adsorption. The similarity of TOF distributions and ESDIAD patterns (right-hand insets) of $\mathrm{O}^{+}$in (a) and (b) indicates that the presence of $\mathrm{BBOH}$ on the $\mathrm{TiO}_{2}(110)$ surface does not change the energy and spatial direction of $\mathrm{O}^{+}$desorption by ESD, consistent with these ions originating from lattice surface $\mathrm{O}^{2-}$ species. Statistically, at 
the low $\mathrm{BBOH}$ coverages employed here, the $\mathrm{O}^{+}$species mainly originate from $\mathrm{O}^{2-}$ lattice sites at a large distance from the $\mathrm{BBOH}$ species.

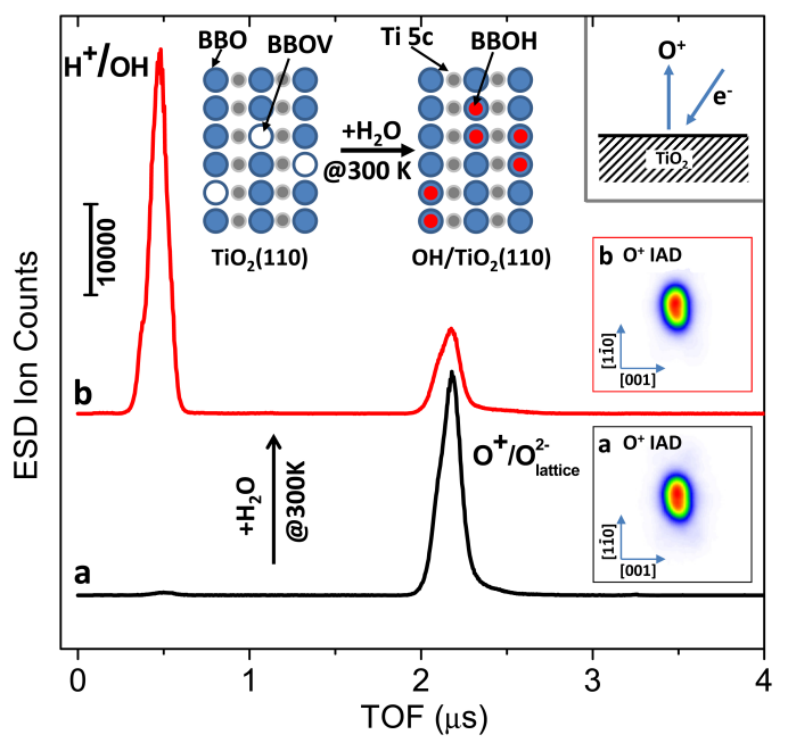

Figure 3.1: Time-of-flight distribution of ESD-produced $\mathrm{H}^{+}$and $\mathrm{O}^{+}$from $\mathrm{TiO}_{2}(110)$ surfaces containing either BBOV (curve a) or BBOH (curve b) surface sites. The production of a small coverage of $\mathrm{BBOH}$ species on the $\mathrm{TiO}_{2}$ surface significantly decreases the $\mathrm{O}^{+}$ESD yield. The ESDIAD patterns of $\mathrm{O}^{+}$indicate that the ion angular distribution (IAD) of $\mathrm{O}^{+}$ions from the lattice sites is unchanged for dissociative $\mathrm{H}_{2} \mathrm{O}$ adsorption.

The coverage of $\mathrm{BBOH}$ sites on the $\mathrm{TiO}_{2}(110)$ surface following $\mathrm{H}_{2} \mathrm{O}$ adsorption can be quantitatively determined by measuring the yield of recombinative desorption of $\mathrm{H}_{2} \mathrm{O}$ from $\mathrm{BBOH}$ association at higher temperature: $2 \mathrm{BBOH} \rightarrow \mathrm{BBO}+\mathrm{BBOV}+\mathrm{H}_{2} \mathrm{O}^{[17]}$. This measurement then permits the fraction of BBOV sites before $\mathrm{H}_{2} \mathrm{O}$ adsorption to be determined. Using this method, the measured coverage of BBOV sites is about $0.1 \mathrm{ML}$ after clean crystal preparation. The measurements are shown in the inset of Figure 3.2 
where the TPD process from 1.5 ML of $\mathrm{H}_{2} \mathrm{O}$ is shown. This total $\mathrm{H}_{2} \mathrm{O}$ desorption consists of a fraction of second-layer $\mathrm{H}_{2} \mathrm{O}$ associated with $\mathrm{BBO}$ sites, a fraction of first-layer $\mathrm{H}_{2} \mathrm{O}$ associated with $\mathrm{Ti}_{5 c}$ sites, and a fraction of $\mathrm{H}_{2} \mathrm{O}$ made by the $\mathrm{BBOH}$ recombination process and observed at the highest temperature ${ }^{[23,84]}$. The derived $\mathrm{BBO}$ coverage for the clean surface is therefore about 0.9 ML, consistent with the work of many others ${ }^{[23,67,84]}$. As $\mathrm{H}_{2} \mathrm{O}$ is adsorbed, as shown in the main part of Figure 3.2, the BBO fractional coverage is found to decrease from 0.9 to $0.8 \mathrm{ML}$ as shown by the blue curve as $\mathrm{BBOH}$ species are produced by water adsorption. The inset to Figure 3.2 shows that the $\mathrm{BBOH}$ coverage reaches a maximum after an exposure to $\sim 5 \times 10^{13} \mathrm{H}_{2} \mathrm{O}$ molecules $/ \mathrm{cm}^{2}$ at $300 \mathrm{~K}$, which produces about 0.2 ML of BBOH species, equivalent to the consumption of about $0.1 \mathrm{ML}$ of BBOV sites. Our central finding is that the effect of the addition of an $\mathrm{OH}$ species influences about $5 \mathrm{x}$ as many neighbor $\mathrm{O}^{2-}$ lattice sites by shutting down $\mathrm{O}^{+}$formation in ESD. The factor of 5 magnification in the fractional loss of $\mathrm{O}^{+}$ESD signal compared to the production of BBOH species ( 0.1 ML) argues persuasively that a simple geometrical site blocking model is inappropriate and that instead a longer-range ESD quenching effect across the $\mathrm{TiO}_{2}$ surface, originating from the formation of $\mathrm{BBOH}$ species, is being observed. This long range effect is postulated to be due to the redistribution of defect-site electrons across the surface when $\mathrm{BBOH}$ species are formed at $\mathrm{BBOV}$ sites, which will be discussed later. 


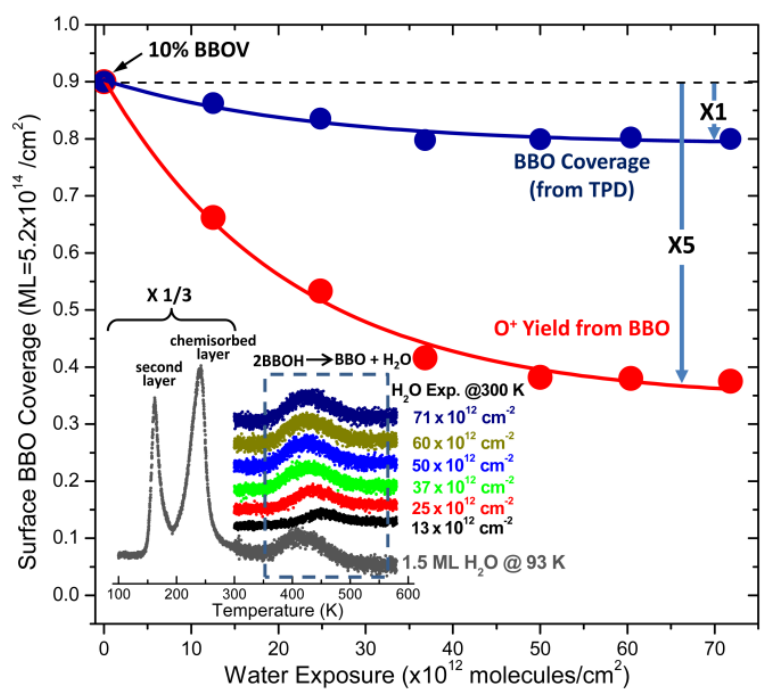

Figure 3.2: The influence of water exposure on the $\mathbf{O}^{+}$ESD yields. Inset shows the TPD spectra of $\mathbf{H}_{2} \mathrm{O}$ on the $\mathrm{TiO}_{2}(\mathbf{1 1 0})$ surface showing that $2 \mathrm{BBOH} \rightarrow \mathrm{BBO}+\mathrm{BBOV}+\mathrm{H}_{2} \mathrm{O}$ occurs near 420 $\mathrm{K}$. The $\mathrm{BBO}$ coverage (blue dots) on the water-exposed $\mathrm{TiO}_{2}(110)$ surface at $300 \mathrm{~K}$ is calculated by the comparison of the $\mathrm{H}_{2} \mathrm{O}$ recombinative desorption yield to the $\mathrm{H}_{2} \mathrm{O}$ yield from $1.5 \mathrm{ML} \mathrm{H}_{2} \mathrm{O}$ at 93K. The red dots indicate the $\mathrm{O}^{+}$ESD yield from $\mathrm{BBO}$ related to the $\mathrm{O}^{+}$yield from the clean $\mathrm{TiO}_{2}(110)$ surface, both of which are normalized to the initial BBO concentration (0.9). A negative temperature measurement error of $\sim 70 \mathrm{~K}$ near $400 \mathrm{~K}$ exists in the TPD spectra.

To further test the idea that the spreading of electron density at the $\mathrm{TiO}_{2}$ surface significantly influences the production of $\mathrm{O}^{+}$ions by ESD, we employed the adsorption of both electron-acceptor molecules and electron-donor molecules to remove or add electron density to the surface as shown in Figure 3.3. Electron acceptor molecules, ${ }^{15} \mathrm{~N}^{18} \mathrm{O}$ and ${ }^{18} \mathrm{O}_{2}$ were employed to trap the spread-out defect-electrons. Oxygen isotopic labeling of the electron acceptor molecules was used to eliminate interference with measurements of the ${ }^{16} \mathrm{O}^{+}$ESD yield from the $\mathrm{TiO}_{2}$ lattice. The transfer of electrons from hydroxylated 
$\mathrm{TiO}_{2}(110)$ to adsorbed NO has been shown to occur using STM and XPS measurements as well as by DFT calculations ${ }^{[21]}$. The transfer of electrons from the hydroxylated $\mathrm{TiO}_{2}(110)$ to adsorbed $\mathrm{O}_{2}$ has also been measured by EELS ${ }^{[15]}$. For both acceptor molecules used here, it was found that transfer of charge from the surface strongly increases the yield of $\mathrm{O}^{+}$, as expected for the partial removal of the spread-out defect-electrons. In contrast, the electron-donor molecules, $\mathrm{ND}_{3}$ and $\mathrm{C}_{5} \mathrm{H}_{5} \mathrm{~N}$, cause a decrease in the $\mathrm{O}^{+}$ion ESD yield from the $\mathrm{TiO}_{2}$ lattice as shown in the bottom of Figure 3.3. This is caused by the enhancement of electron density on the surfaces by the donor molecules. 


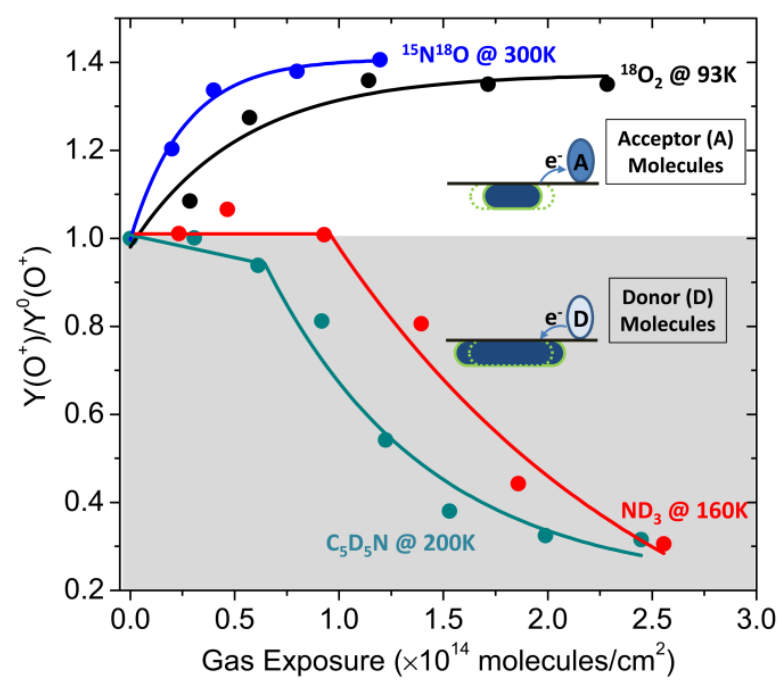

Figure 3.3: Manipulation of electron density at the hydroxylated $\mathrm{TiO}_{2}$ surface. The adsorption of electron acceptor molecules $\left({ }^{15} \mathrm{~N}^{18} \mathrm{O},{ }^{18} \mathrm{O}_{2}\right)$ enhances the $\mathrm{O}^{+} \mathrm{ESD}$ yields due to the electron transfer from $\mathrm{TiO}_{2}$ to the acceptor molecule causing a loss of delocalized electron density across the $\mathrm{TiO}_{2}$ surface. On the other hand, the presence of electron donor molecules $\left(\mathrm{ND}_{3}, \mathrm{C}_{5} \mathrm{D}_{5} \mathrm{~N}\right)$ decreases the $\mathrm{O}^{+}$ESD yields due to the electron transfer from the donor molecule to $\mathrm{TiO}_{2}$ causing an enhancement of delocalized electron density. The inactive zone at low coverages of the donor molecules is due to their initial adsorption on $\mathrm{BBOH}$ groups by hydrogen bonding ${ }^{[85-86]}$.

The spatial distribution of defect electrons associated with BBOV defect sites on the $\mathrm{TiO}_{2}(110)$ surface is schematically indicated in Figure 3.4a. These electrons, while associated with the $\mathrm{O}^{2-}$ vacancy, may be distributed amongst $\mathrm{Ti}^{4+}$ ions at a depth of one or two lattice distances under the surface. ${ }^{[65,74,76-79]}$ After dissociative adsorption of water, the defect-electrons redistribute along the surface. This is possibly related to the lattice relaxation by the filling of BBOV sites with $\mathrm{BBOH}$ species. The electron-spreading effect is schematically indicated by the small red hatched regions at surface-Ti sites. Using DFT 
calculations, Liu et al. ${ }^{[19]}$ found that the presence of $\mathrm{BBOH}$ on $\mathrm{TiO}_{2}(110)$ surface causes the spread of defect-related electrons along the [001] direction, in agreement with this general idea.

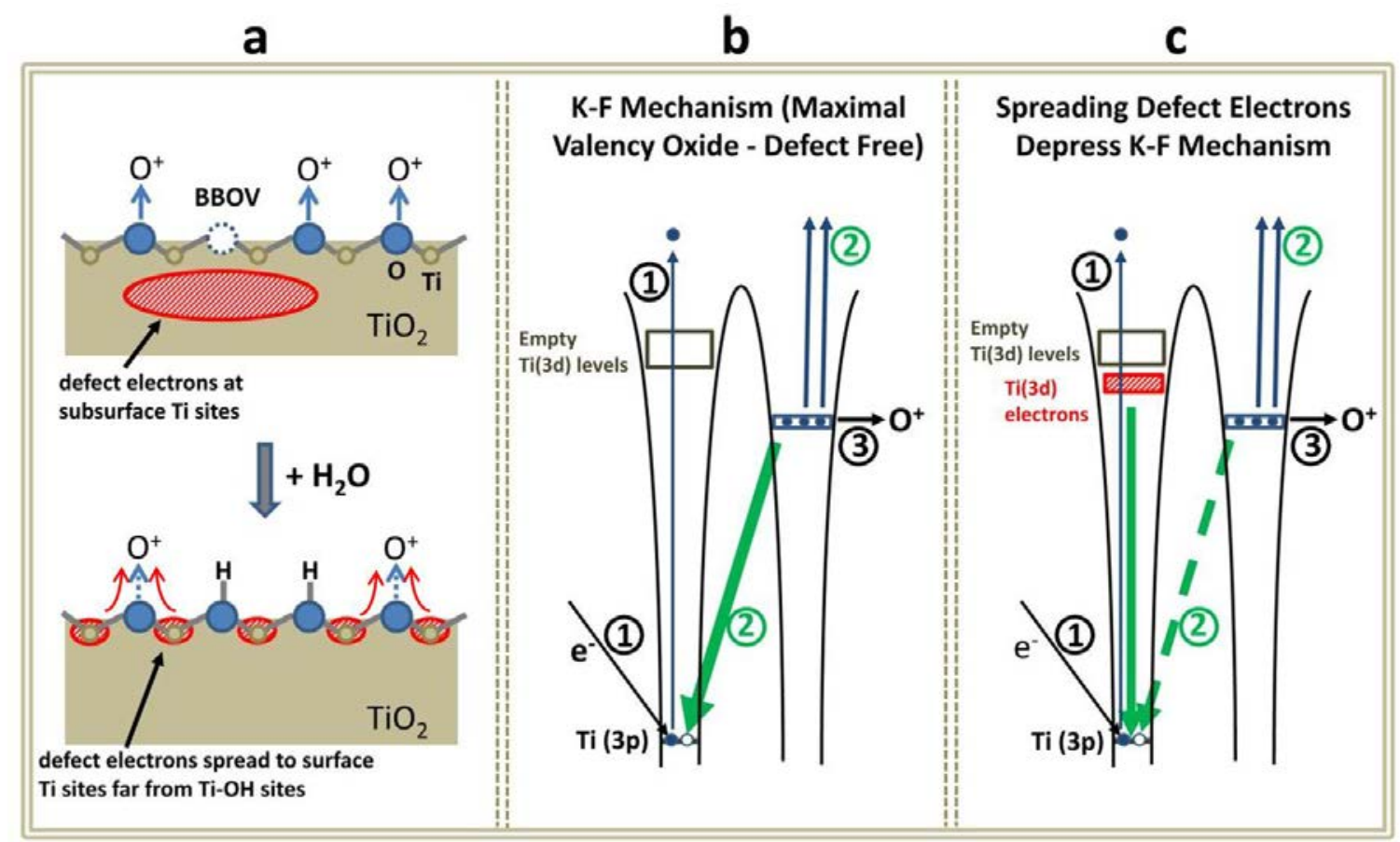

Figure 3.4: The influence of Ti(3d) electron distribution on the $\mathrm{O}^{+}$ESD yields. (a). The schematic distributions of defect electrons on $\mathrm{TiO}_{2}(110)$ surface with BBOV sites (upper part) and BBOH sites (lower part). (b). Schematic diagram of Knotek-Feibelman (K-F) mechanism for $\mathrm{O}^{+}$ESD from a $\mathrm{TiO}_{2}$ surface triggered by the production of a hole in the $\mathrm{Ti}(3 \mathrm{p})$ level; (c). The influence of defect $\mathrm{Ti}(3 \mathrm{~d})$ electron distribution on the K-F mechanism, showing that a spread-out electron distribution influencing multiple $\mathrm{Ti}(3 \mathrm{p})$ sites enhances the transitions from the $\mathrm{Ti}(3 \mathrm{~d})$ electrons to Ti(3p) hole sites, depressing the K-F $\mathrm{O}^{+}$-yield in processes 2 and 3.

The depression of the $\mathrm{O}^{+}$ion yield in ESD on the hydroxylated $\mathrm{TiO}_{2}(110)$ surface by the redistribution of defect-electrons along the surface may occur via two mechanisms: (i) 
The redistributed electrons can depress the initial formation of $\mathrm{O}^{+}$at the initial stage (initial state ionization effect); (ii) The redistributed electrons can more effectively reneutralize the $\mathrm{O}^{+}$ions formed by ESD (final state reneutralization effect).

(i) Initial State Ionization Effect: The generation of $\mathrm{O}^{+}$ions by ESD on $\mathrm{TiO}_{2}$ has been proposed to occur by a well-known process - the Knotek-Feibelman (K-F) process as shown in Figure 3.4b ${ }^{[56]}$. According to the K-F model, the maximal valency defect-free oxide (stoichiometric $\mathrm{TiO}_{2}$ ) containing only $\mathrm{Ti}^{4+}$ ions in the surface and throughout the bulk, contains no electron density in the empty Ti(3d) valence band. When an incident electron (with a threshold energy of $\sim 34 \mathrm{eV}$ ) ${ }^{[56,87]}$ excites the semiconductor $\mathrm{TiO}_{2}$ by process 1 , the ejection of an electron occurs from the Ti(3p) core level. Since there is no $\mathrm{Ti}$ electron density in the empty valence band, an interatomic Auger transition - process 2, heavy solid green arrow involving $\mathrm{O}(2 \mathrm{p})$ electrons - takes place to fill the Ti(3p) hole. To conserve energy, two additional $\mathrm{O}(2 \mathrm{p})$ electrons are also ejected in process 2 , leaving an $\mathrm{O}^{+}$ lattice ion where an $\mathrm{O}^{2-}$ surface lattice ion was originally present. A Coulomb explosion, ejecting the $\mathrm{O}^{+}$ion from the lattice containing repulsive $\mathrm{Ti}^{4+}$ ions is the result, and lattice $\mathrm{O}^{+}$is observed to desorb in ESD - process 3. In a traditional Auger transition, valence electrons of the Ti atom would fall into the Ti(3p) hole (intra-atomic Auger transition) but in maximal valency oxides this is impossible, and the less probable interatomic Auger transition occurs. Therefore, the $\mathrm{O}^{+}$ESD yield by the K-F process should vary inversely 
with the occupancy of valence orbitals on the $\mathrm{Ti}^{4+}$ ions in the surface. Oxygen-vacancy (BBOV) defect sites, produce defect electron density at $\mathrm{Ti}^{4+}$ sites which participate in the downward Auger transition, shutting down the K-F mechanism and reducing the $\mathrm{O}^{+}$-ESD yield. We postulate that the formation of $\mathrm{BBOH}$ species at $\mathrm{BBOV}$ sites causes the lateral redistribution of defect-electrons, causing the interatomic Auger transition to occur over a large region on the $\mathrm{TiO}_{2}$ surface extending beyond the $\mathrm{BBOH}$ site, thereby further reducing the ESD yield of $\mathrm{O}^{+}$ions by the K-F mechanism.

The BBOH-induced spreading of electrons to neighbor $\mathrm{Ti}^{4+}$ sites enhances the overall probability of transition from the $\operatorname{Ti}(3 \mathrm{~d})$ electrons to the $\operatorname{Ti}(3 \mathrm{p})$ holes, thereby short circuiting the K-F interatomic Auger process. This is shown in Figure 3.4c where the distribution of the defect electrons to multiple $\mathrm{Ti}(3 \mathrm{~d})$ sites is schematically represented by the cross-hatched regions. The suppression of the interatomic Auger process (short green dashes), caused by increased defect electron spreading along the surface, is accompanied by a decrease in $\mathrm{O}^{+}$yield by ESD over a wide area, as the K-F mechanism is shut down extensively. The formation of one $\mathrm{BBOH}$ site is responsible for suppression of the K-F mechanism at $\sim 5$ neighbor sites.

As a comparison, the $\mathrm{H}^{+}$ESD yields with the water exposure have also been investigated (Figure 3.5). The $\mathrm{H}^{+}$ESD yield scales proportionally to the $\mathrm{BBOH}$ coverage. This is reasonable because the $\mathrm{H}^{+}$ESD has a threshold energy at the $\mathrm{O}(2 \mathrm{~s})$ ionization not 
the $\mathrm{Ti}(3 \mathrm{p})$ ionization energy, ${ }^{[87]}$ which means the redistribution of $\mathrm{Ti}(3 \mathrm{~d})$ electrons cannot influence the $\mathrm{H}^{+}$yields through the K-F mechanism.

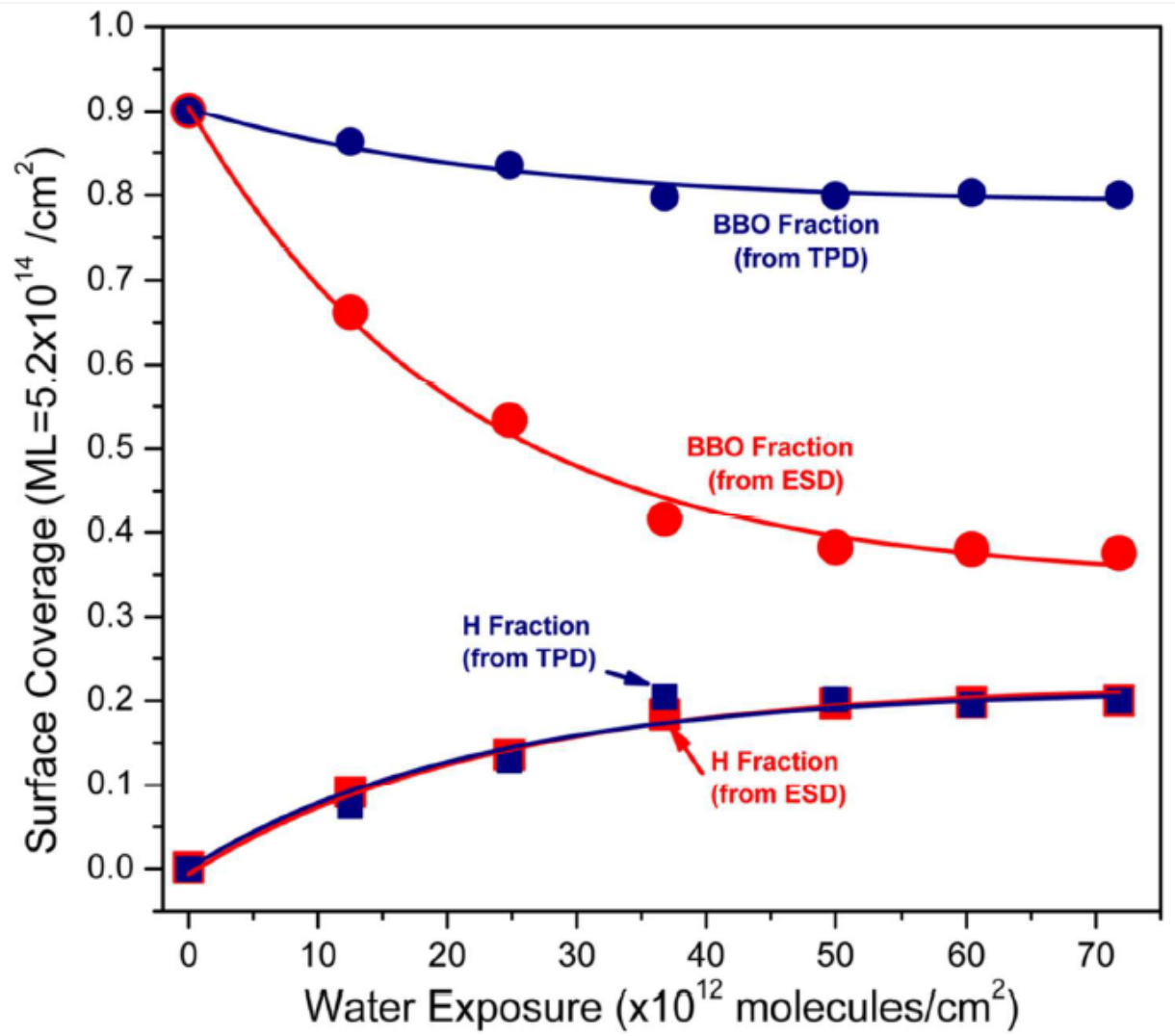

Figure 3.5: The $\mathrm{BBO}$ (blue dots) and $\mathrm{BBOH}$ (blue squares) show the coverages on the water-exposed $\mathrm{TiO}_{2}(110)$ surface at $300 \mathrm{~K}$ calculated from the magnitude of the $\mathrm{H}_{2} \mathrm{O}$ recombinative TPD peaks. The red dots (squares) indicate the $\mathrm{O}^{+}\left(\mathrm{H}^{+}\right)$ESD yield, which are normalized to the initial (final) BBO (BBOH) concentration. It is clearly seen that the fractional decrease in the $\mathrm{O}^{+}$yield far exceeds the fractional decrease in $\mathrm{BBO}$ coverage during $\mathrm{H} 2 \mathrm{O}$ adsorption.

It should be mentioned that the assumption of completely empty $\mathrm{Ti}(3 \mathrm{~d})$ orbitals in stoichiometric $\mathrm{TiO}_{2}$ in the $\mathrm{K}-\mathrm{F}$ mechanism is not strictly correct due to some degree of 
covalency of $\mathrm{Ti}(3 \mathrm{~d})$ and $\mathrm{O}(2 \mathrm{p})$ orbitals. ${ }^{\left[{ }^{9,}\right.}{ }^{88]}$ Based on electron-ion coincidence spectroscopy measurements, Tanaka et al. ${ }^{[89]}$ defined a new ionization mechanism in $\mathrm{TiO}_{2}$ and proposed that instead of the interatomic Auger process in the K-F mechanism, electrons can directly transfer from the $\mathrm{O}(2 \mathrm{p})$ orbitals to $\mathrm{Ti}(3 \mathrm{~d})$ orbitals due to the pulled-down $\mathrm{Ti}(3 \mathrm{~d})$ energy level by the $\mathrm{Ti}(3 \mathrm{p})$ core hole leading to $\mathrm{O}^{+}$ejection. In this proposed mechanism, also, the enhancement of $\mathrm{Ti}(3 \mathrm{~d})$ electron availability can diminish the charge transfer between $\mathrm{Ti}(3 \mathrm{~d})$ and $\mathrm{O}(2 \mathrm{p})$, decreasing $\mathrm{O}^{+}$production.

(ii) Final State Reneutralization Effect: The excited $\mathrm{O}^{+}$ions can also be reneutralized by the electrons transferred from the substrate or neighboring atoms, and thus the $\mathrm{O}^{+} \mathrm{ESD}$ yield decreases. ${ }^{[90-92]}$ Within the framework of this model, the spreading of electron density by $\mathrm{BBOH}$ formation to neighbor sites would enhance $\mathrm{O}^{+}$neutralization.

It is not possible based on these experiments with $\mathrm{BBOH}$ groups or with donor and acceptor adsorbate molecules to discriminate between the initial and final state models proposed above.

\subsection{Conclusions}

In summary, we have shown that longer-range defect electron spreading may be chemically induced for electrons originally associated with oxygen vacancy defect sites on $\mathrm{TiO}_{2}(110)$. This longer range effect is postulated to be due to the redistribution of 
defect-site electrons when $\mathrm{BBOH}$ species are formed at BBOV sites. This general finding is supported by the behavior of the $\mathrm{O}^{+}$yield in ESD, which is found to respond to electron donor/acceptor effects on the spread-out electrons. This finding may shed new light on the electronic behavior of oxide surfaces because of the dominant role of hydroxyl species in the surface chemistry of oxides of all types ${ }^{[00,93]}$. For example, the longer-range interaction between $\mathrm{BBOH}$ and $\mathrm{O}_{2}$ on the $\mathrm{TiO}_{2}(110)$ surface was investigated by DFT calculations, indicating that the spatial redistribution of defect-electrons may govern the $\mathrm{O}_{2}$-supply pathways for $\mathrm{CO}$ catalytic oxidation on $\mathrm{Au} / \mathrm{TiO}_{2}$ catalyst surfaces ${ }^{[19]}$. 


\section{CHAPTER FOUR: A New Form of Chemisorbed Atomic $\mathrm{H}$ on the $\mathrm{TiO}_{2}(110)$ Surface}

\subsection{Abstract}

A new form of chemically-bound hydrogen, $\mathrm{H} / \mathrm{TiO}_{2}$, on the $\mathrm{TiO}_{2}(110)$ surface is produced by exposure to atomic $\mathrm{H}$ at $87 \mathrm{~K}$. This chemisorbed hydrogen differs significantly in its physical and chemical properties from $\mathrm{OH} / \mathrm{TiO}_{2}$ species $(\mathrm{BBOH})$ produced from $\mathrm{H}_{2} \mathrm{O}$ dissociative adsorption. The $\mathrm{H} / \mathrm{TiO}_{2}$ species produces a normal beam of $\mathrm{H}^{+}$upon electron stimulated desorption whereas $\mathrm{OH} / \mathrm{TiO}_{2}$ species produce inclined $\mathrm{H}^{+}$ ESD beams. By $\sim 350 \mathrm{~K}, \mathrm{H} / \mathrm{TiO}_{2}$ has desorbed thermally whereas $\mathrm{OH} / \mathrm{TiO}_{2}$ begins to desorb as $\mathrm{H}_{2} \mathrm{O}$ only above $\sim 350 \mathrm{~K}$. Remarkably, $\mathrm{H} / \mathrm{TiO}_{2}$ exhibits an extremely large ESD cross section $\left(7.1 \times 10^{-14} \mathrm{~cm}^{2}\right)$, while the cross section for $\mathrm{OH} / \mathrm{TiO}_{2}$ is estimated to be $\sim 10^{-20} \mathrm{~cm}^{2}$. Moreover, $\mathrm{H} / \mathrm{TiO}_{2}$ is highly sensitive to $\mathrm{UV}$ photon desorption, while $\mathrm{OH} / \mathrm{TiO}_{2}$ is inactive to UV.

\subsection{Introduction}

Surface-bound hydrogen species on $\mathrm{TiO}_{2}$ surfaces are involved in solar-driven reduction processes such as in the production of useful hydrogenated organic products from $\mathrm{CO}_{2}$ and $\mathrm{H}_{2} \mathrm{O}$ as well as $\mathrm{H}_{2}$ from $\mathrm{H}_{2} \mathrm{O}^{[1]}$. Such photochemical reduction processes 
could become important in the capture, storage and transport of solar energy. Also in heterogeneous catalysis, atomic $\mathrm{H}$ spilled over from $\mathrm{H}_{2}$ dissociation from metals supported on $\mathrm{TiO}_{2}{ }^{[32,94]}$, and other oxides ${ }^{[95-96]}$ or other metals ${ }^{[97-98]}$, is important in surface reduction processes in the absence of light activation. Additionally, the absorption of $\mathrm{H} \mathrm{in} \mathrm{TiO}_{2}$ significantly changes the $\mathrm{TiO}_{2}$ geometric and electronic structure, increasing the solar light absorption efficiency and photocatalytic activity ${ }^{[99]}$.

The rutile- $\mathrm{TiO}_{2}(110)$ surface is the prototype oxide surface, widely studied as a model photocatalytic material ${ }^{[8-9,90-61]}$ (band gap $=3.1 \mathrm{eV}$ ) as well as a model support for metallic catalyst particles $^{[100-103]}$. It is a reducible oxide which may be partially reduced by heating in vacuum to $950 \mathrm{~K}$ and often exhibits up to $10 \%$ oxygen-vacancy defects at its surface. In the bulk, while it can be made stoichiometric, it easily forms bulk oxygen vacancy defects $^{[9]}$ and associated $\mathrm{Ti}^{3+}$ interstitial species ${ }^{[64,104]}$ upon heating in vacuum. The non-stoichiometric character of $\mathrm{TiO}_{2}$ causes it to be an n-type semiconductor. The rutile- $\mathrm{TiO}_{2}(110)$ surface is the thermodynamically most stable $\mathrm{TiO}_{2}$ crystal surface.

As is common for all oxide surfaces, hydroxyl functional group bonding predominates. For $\mathrm{TiO}_{2}(110)$, Ti-OH groups can be made from water adsorption at oxygen vacancy defects producing $2 \mathrm{OH}$ groups $(\mathrm{BBOH})$ per adsorbed $\mathrm{H}_{2} \mathrm{O}$ molecule ${ }^{[14,22,63]}$.

On the other hand, the adsorption of atomic $\mathrm{H}$ on the $\mathrm{TiO}_{2}(110)$ surface has not been well studied but it has been reported that atomic $\mathrm{H}$ interacts with $\mathrm{TiO}_{2}(110)$ to 
produce a Ti-OH surface species ${ }^{[33]}$ in contrast to the work reported here. We demonstrate here the unique properties of the hydrogen surface species produced by atomic $\mathrm{H}$ adsorption which is bound to the $\mathrm{TiO}_{2}(110)$ surface in a new manner, differing from Ti-OH.

Electron bombardment of $\mathrm{TiO}_{2}(110)$ to cause electron stimulated desorption (ESD) has been used here to characterize the chemisorbed $\mathrm{H}$ species by the observation of the $\mathrm{H}^{+}$fragment product. H-bonding information is derived from the characterization of the $\mathrm{H}^{+}$kinetic energy, the measurement of the cross section for $\mathrm{H}^{+}$ desorption in ESD, and the characterization of the $\mathrm{H}^{+}$angular distribution. We have used time-of-flight electron stimulated desorption (TOF-ESDIAD) and the measurement of total cross section for electron stimulated desorption along with the $\mathrm{H}^{+}$ion angular distributions by TOF-ESDIAD to characterize the new form of surface $\mathrm{H}$ (we tentatively term it as $\mathrm{Ti}-\mathrm{H}$ ), and to clearly distinguish it from Ti-OH species. In addition, $\mathrm{UV}$ induced photodesorption of $\mathrm{H} / \mathrm{TiO}_{2}$ has been observed and the cross section for photodesorption has been measured.

\subsection{Experimental Section}

This experiment was conducted in a stainless steel UHV chamber (base pressure below $5 \times 10^{-11}$ mbar) equipped with a combined time-of-flight electron stimulated 
desorption ion angular distribution (TOF-ESDIAD) and pulse counting low energy electron diffraction (LEED) apparatus, a cylindrical-mirror-analyzer-Auger electron spectrometer (CMA-AES), and an apertured quadrupole mass spectrometer (QMS) and a ultraviolet source. A $\mathrm{TiO}_{2}(110)-(1 \times 1)$ crystal (Princeton Scientific, $7 \times 7 \times 1 \mathrm{~mm}^{3}$ ) with BBOV density of $\sim 6 \%$ BBO sites on the surface was prepared by cycles of $\mathrm{Ar}^{+}$sputtering and annealing in UHV at $950 \mathrm{~K}$. The cleanliness and surface structure of the $\mathrm{TiO}_{2}(110)-(1 \times 1)$ surface was confirmed by AES and LEED, respectively. A partially-hydroxylated $\mathrm{TiO}_{2}(110)$ surface $\left(\mathrm{OH} / \mathrm{TiO}_{2}\right)$ was prepared by exposing to water vapor at $320 \mathrm{~K}$ from a calibrated and collimated molecular beam source. A hydrogenated $\mathrm{TiO}_{2}(110)$ surface $\left(\mathrm{H} / \mathrm{TiO}_{2}\right)$ was prepared by exposing to atomic $\mathrm{H}$ at $87 \mathrm{~K}$ produced by pyrolysis of $1 \times 10^{-7} \mathrm{mbar}_{2}$ through background dosing on a $\sim 1800 \mathrm{~K}$ tungsten filament. A PYRO Micro-Optical Pyrometer Set was used to measure the temperature of the tungsten filament. The ESD experiments on the $\mathrm{TiO}_{2}(110)$ surface employed pulsed $180 \mathrm{eV}$ electrons at 2-40 kHz with $75 \mathrm{~ns}$ width, leading to different electron fluxes. The produced positive ions were separated by their time-of-flight caused by the ion mass difference ${ }^{[83]}$. A $+30 \mathrm{~V}$ bias was applied to the crystal during the ESDIAD measurements.

\subsection{Results and Discussion}

Using $210 \mathrm{eV}$ electrons and a pulse-counting ion angular distribution apparatus, it is found that both adsorbed $\mathrm{OH}$ (from partial monolayer (ML) $\mathrm{H}_{2} \mathrm{O}$ adsorption) and $\mathrm{H}$ from 
atomic $\mathrm{H}$ adsorption yield almost identical $\mathrm{H}^{+}$TOF distributions shown in Figure 4.1A. The $0.5 \mu$ s flight time, corrected for ion acceleration in the apparatus, corresponds to an $\mathrm{H}^{+}$ kinetic energy $=9 \pm 3 \mathrm{eV}$ for ESD from both $\mathrm{H} / \mathrm{TiO}_{2}$ and $\mathrm{OH} / \mathrm{TiO}_{2}$ adsorbed species. While the ion energies are very similar, the ion angular distributions differ significantly as shown in Figure 4.1B and 4.1C. $\mathrm{H} / \mathrm{TiO}_{2}$ yields an almost circular normally-oriented $\mathrm{H}^{+}$ angular distribution while $\mathrm{OH} / \mathrm{TiO}_{2}$ yields a highly elongated $\mathrm{H}^{+}$angular distribution. The elongation is in the $[1 \overline{1} 0]$ direction perpendicular to the rows of bridge-bonded oxygen (BBO) species as shown in the insert to Figure 4.1A. The normal $\mathrm{H}^{+}$ESDIAD pattern for $\mathrm{H} / \mathrm{TiO}_{2}$ indicates that the $\mathrm{Ti}-\mathrm{H}$ bond is normally-oriented to the surface, while the elongated $\mathrm{H}^{+}$ESDIAD pattern for $\mathrm{OH} / \mathrm{TiO}_{2}$ indicates that the $\mathrm{O}-\mathrm{H}$ bonds are inclined to the left or right in the $[1 \overline{1} 0]$ direction, or alternatively that high amplitude $\mathrm{OH}$ bending modes are present. The $\mathrm{H} / \mathrm{TiO}_{2}$ species produced from pyrolysis of $\mathrm{H}_{2}$ by a hot $\mathrm{W}$ filament is always accompanied by fractions of a monolayer of inclined $\mathrm{OH} / \mathrm{TiO}_{2}$ species due to impurity $\mathrm{H}_{2} \mathrm{O}$ adsorption. 


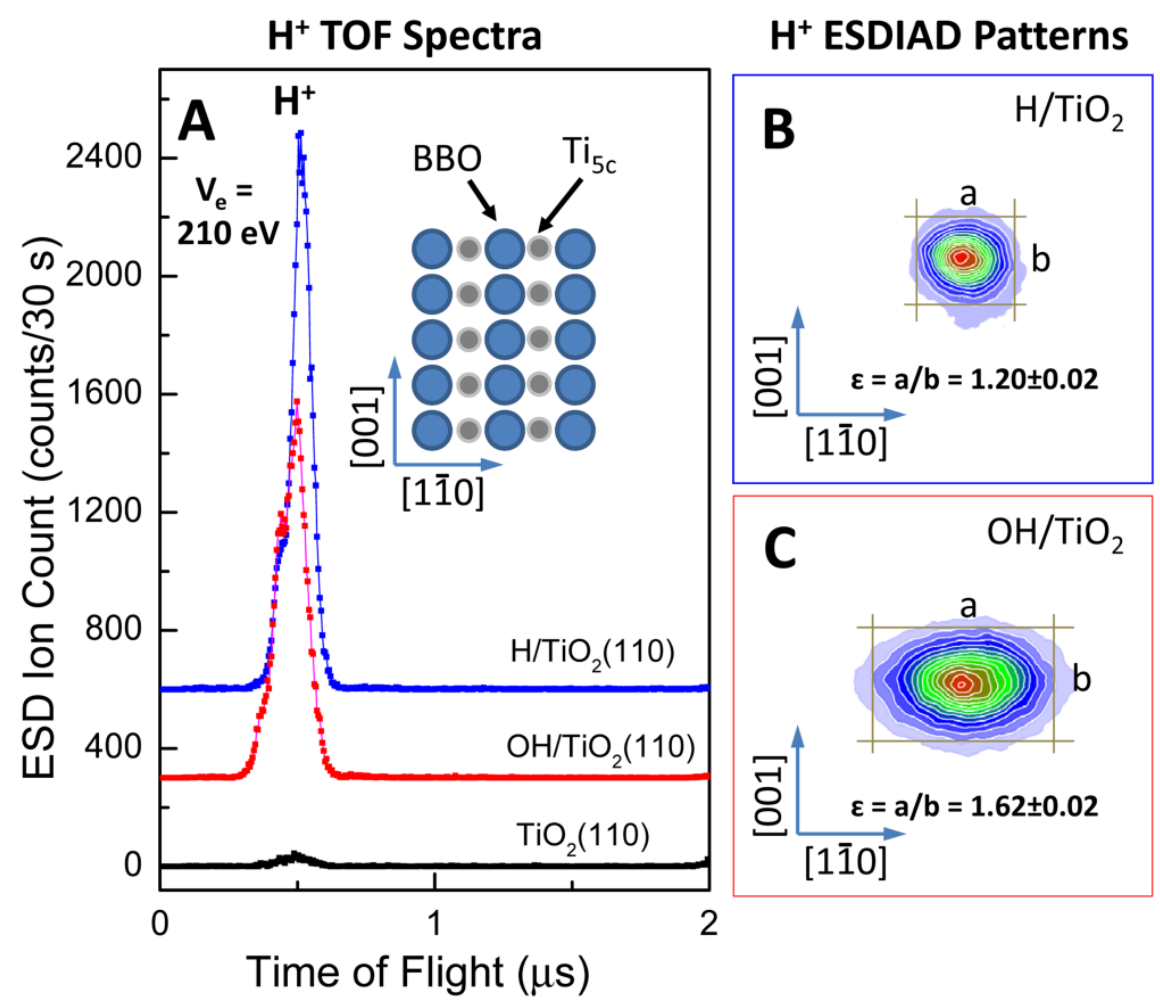

Figure 4.1: Electron stimulated desorption of $\mathrm{H} / \mathrm{TiO}_{2}$ and $\mathrm{OH} / \mathrm{TiO}_{2}$. (A). Time-of-flight spectra of $\mathrm{H}^{+}$produced by $210 \mathrm{eV}$ electron bombardment on $\mathrm{TiO}_{2}(110), \mathrm{OH} / \mathrm{TiO}_{2}(110)$ and $\mathrm{H} / \mathrm{TiO}_{2}(110)$ surfaces. (B) and (C). $\mathrm{H}^{+}$ion angular distribution patterns on $\mathrm{H} / \mathrm{TiO}_{2}$ and $\mathrm{OH} / \mathrm{TiO}_{2}$ surfaces. In (B), the contribution of $\mathrm{OH} / \mathrm{TiO}_{2}$ is removed by thermal treatment of the surface based on the behavior shown in Figure 4.2.

The thermal properties of $\mathrm{H} / \mathrm{TiO}_{2}$ and $\mathrm{OH} / \mathrm{TiO}_{2}$ differ greatly as shown in Figure 4.2. Here we use the yield of $\mathrm{H}^{+}$by ESD for study of the two surface hydrogenic species. For $\mathrm{H} / \mathrm{TiO}_{2}$, depletion by heating in vacuum occurs up to $\sim 350 \mathrm{~K}$ as shown in Figure 4.2A, followed by a fractional ML remaining coverage of $\mathrm{OH} / \mathrm{TiO}_{2}$ depletion above $\sim 350 \mathrm{~K}$. The $\mathrm{OH}$ is inadvertently added to the surface 
during bombardment by atomic $\mathrm{H}$ from small quantities of $\mathrm{H}_{2} \mathrm{O}$ produced in the ultrahigh vacuum chamber. When only $\mathrm{H}_{2} \mathrm{O}$ is adsorbed, to produce only $\mathrm{OH} / \mathrm{TiO}_{2}$, the behavior of the $\mathrm{OH} / \mathrm{TiO}_{2}$ upon heating is shown in Figure 4.2B, indicating that $\mathrm{OH} / \mathrm{TiO}_{2}$ thermal depletion occurs only above $\sim 350 \mathrm{~K}$. From the data in Figure 4.2, we see that saturation coverage of $\mathrm{H} / \mathrm{TiO}_{2}$ above the background due to $\mathrm{OH} / \mathrm{TiO}_{2}$ gives about $19 \times 10^{3} \mathrm{H}^{+}$counts/30 s, whereas the saturation coverage of $\mathrm{OH} / \mathrm{TiO}_{2}$ gives about $33 \times 10^{3} \mathrm{H}^{+}$counts/30 s. These count rates are consistent with those measured by integration in Figure 4.1A. The thermal stability of $\mathrm{OH} / \mathrm{TiO}_{2}$ shown in Figure 4.2 exceeds that of $\mathrm{H} / \mathrm{TiO}_{2}$, showing that the two kinds of surface hydrogen differ chemically. 


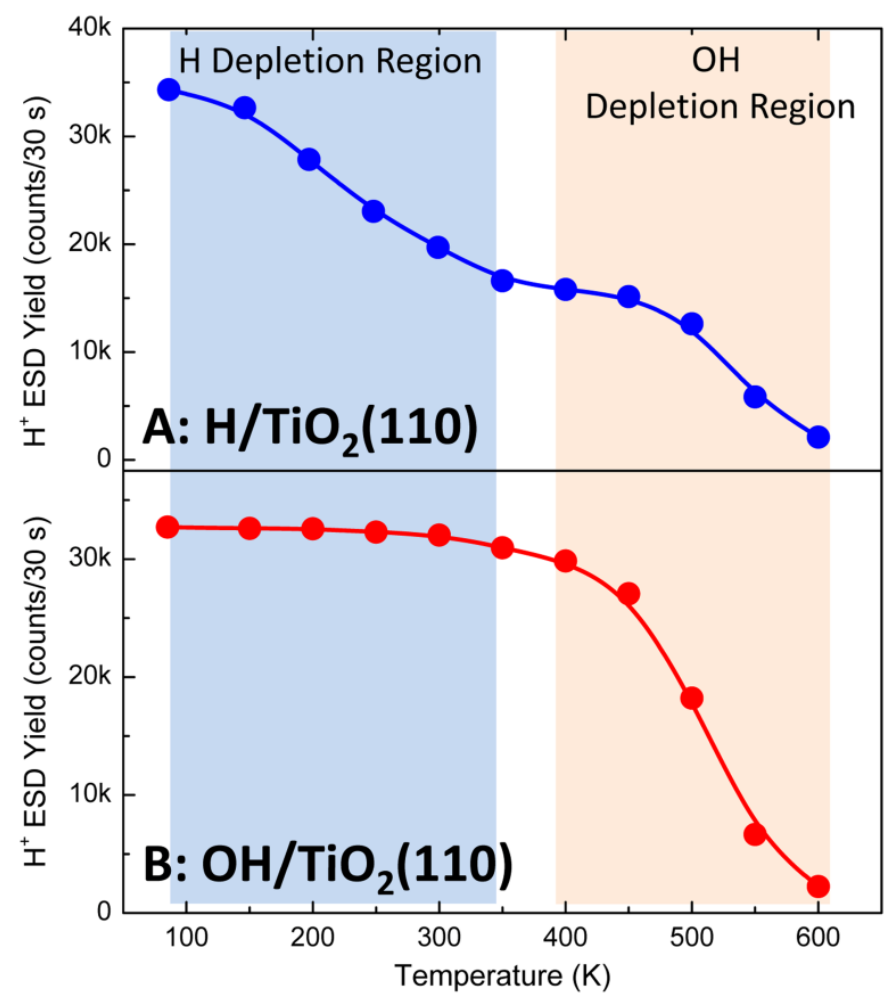

Figure 4.2: Thermal behavior of $\mathrm{H} / \mathrm{TiO}_{2}$ and $\mathrm{OH} / \mathrm{TiO}_{2}$ for desorption into vacuum.

The chemical difference between $\mathrm{H} / \mathrm{TiO}_{2}$ and $\mathrm{OH} / \mathrm{TiO}_{2}$ is also vividly demonstrated by comparing their sensitivity to electron stimulated desorption. Figure 4.3A shows the almost complete lack of sensitivity of $\mathrm{OH} / \mathrm{TiO}_{2}$ to electron stimulated desorption $\left(\mathrm{V}_{\mathrm{e}}=210 \mathrm{eV}\right)$ at an electron flux $\mathrm{F}_{\mathrm{e}}=6.25 \times 10^{10} \mathrm{e} \mathrm{cm}^{-2} \mathrm{~s}^{-1}$. In contrast, for $\mathrm{H} / \mathrm{TiO}_{2}$, for $\mathrm{F}_{\mathrm{e}}$ in the range $0.31-3.13 \times 10^{10} \mathrm{e} \mathrm{cm}^{-2} \mathrm{~s}^{-1}$, a monotonically increasing and large rate of $\mathrm{H}$ depletion by ESD is observed. $\mathrm{H} / \mathrm{TiO}_{2}$ is very sensitive to electrons and responds both by ionization to produce $\mathrm{H}^{+}$and by the breaking of the $\mathrm{H} / \mathrm{TiO}_{2}$ bond by $210 \mathrm{eV}$ electrons. Data like that shown in Figure 4.3A are combined 
to show the $\mathrm{H} / \mathrm{TiO}_{2}$ exponential decay time during ESD. The exponential dependence in Figure 4.3B was used to derive the cross section of ESD of $\mathrm{H} / \mathrm{TiO}_{2}$, and a cross section value of $\mathrm{Q}=7.1 \times 10^{-14} \mathrm{~cm}^{2}$ is found. This very large cross section indicates that multiple electronic events occur during $210 \mathrm{eV}$ electron bombardment of the $\mathrm{TiO}_{2}(110)$ surface and that the $\mathrm{H}$ atoms from the $\mathrm{H} / \mathrm{TiO}_{2}$ species desorb by excitation processes involving multiple charge carriers produced in the $\mathrm{TiO}_{2}$ by $210 \mathrm{eV}$ electron bombardment. In contrast to the very high cross section for $\mathrm{H} / \mathrm{TiO}_{2}$, the cross section for $\mathrm{OH} / \mathrm{TiO}_{2}$ is estimated to be only $\sim 10^{-20} \mathrm{~cm}^{2}$, a more normal total ESD-cross section. This large contrast in total cross section for ESD of $\mathrm{H}$ from $\mathrm{H} / \mathrm{TiO}_{2}$ and from $\mathrm{OH} / \mathrm{TiO}_{2}$ is again indicative of the large chemical difference between the two kinds of bound $\mathrm{H}$ on the $\mathrm{TiO}_{2}(110)$ surface. 

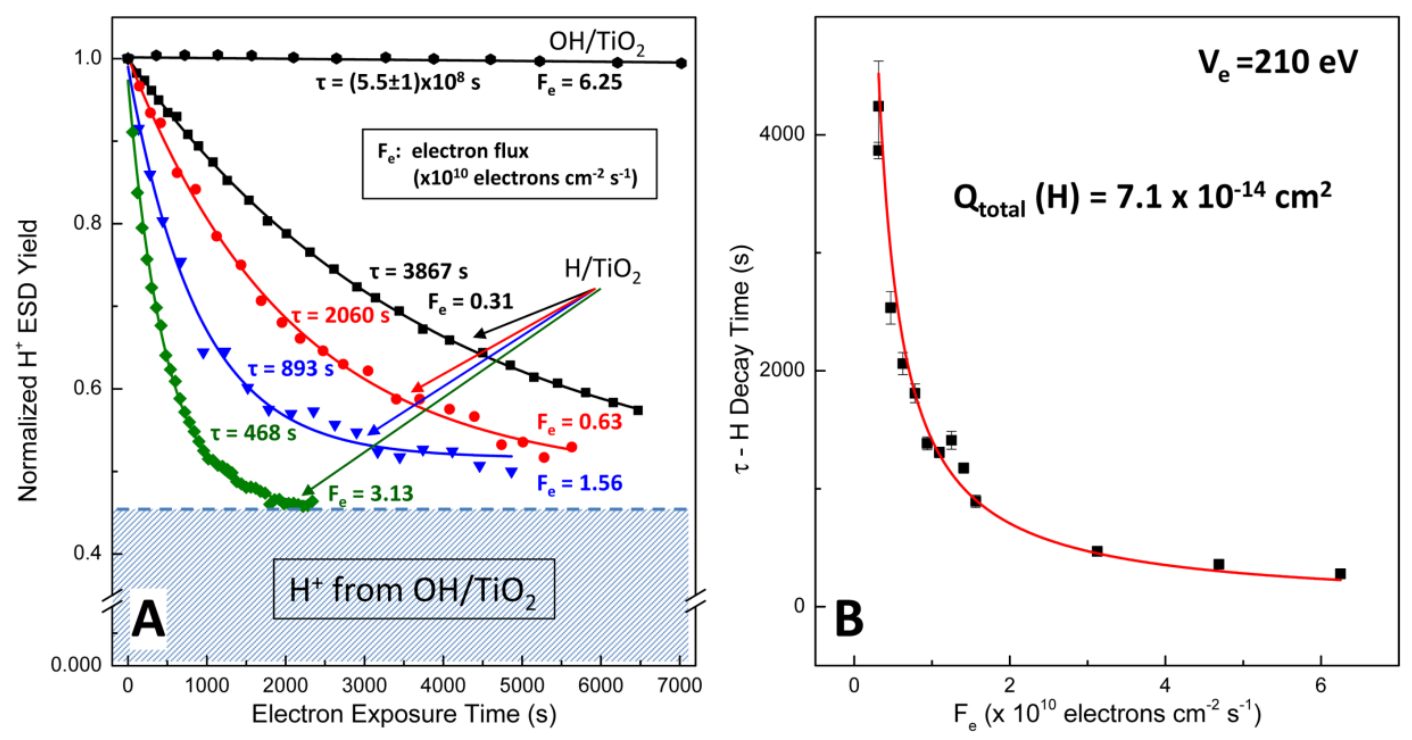

Figure 4.3: $\mathrm{H} / \mathrm{TiO}_{2}$ - ESD cross section measurement.

The TOF-ESDIAD measurement technique also permits us to measure the influence of UV irradiation on the coverage of $\mathrm{H} / \mathrm{TiO}_{2}$ by monitoring the $\mathrm{H}^{+}$-ESD yield during $\mathrm{UV}$ irradiation. Using (for analysis) only the ESD production of $\mathrm{H}^{+}$from $\mathrm{H} / \mathrm{TiO}_{2}\left(\right.$ at $\mathrm{F}_{\mathrm{e}}=6.25 \times$

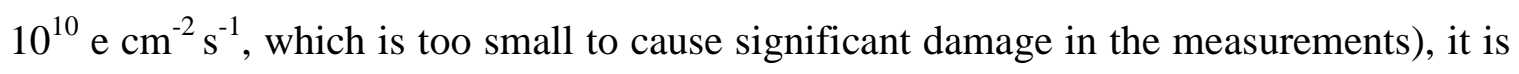
seen that $\mathrm{H} / \mathrm{TiO}_{2}$ species are also able to be desorbed by UV photons of $3.4 \pm 0.1 \mathrm{eV}$ energy, just above the $\mathrm{TiO}_{2}$ bandgap. Figure 4.4 shows the effect of $\mathrm{UV}$ irradiation on $\mathrm{H} / \mathrm{TiO}_{2}$. It may be seen that an exponential decay is observed, and that by $\sim 5 \times 10^{16}$ photons $\mathrm{cm}^{-2}$ exposure, all $\mathrm{H} / \mathrm{TiO}_{2}$ species have been desorbed by UV irradiation. A control experiment in the dark is negative. In addition, $\mathrm{OH} / \mathrm{TiO}_{2}$ is found to be insensitive to $3.4 \mathrm{eV}$ photons.

Figure 4.4 shows that about $50 \mathrm{ML}$ of $3.4 \mathrm{eV}$ photons are capable of completely removing the $\mathrm{H} / \mathrm{TiO}_{2}$ monolayer. The total photodesorption cross section $\left(\sim 10^{-16} \mathrm{~cm}^{2}\right)$ is $\sim 10^{-3}$ that of 
the ESD process caused by $210 \mathrm{eV}$ electrons, as determined by the exponential fit. It is clear that $\mathrm{H} / \mathrm{TiO}_{2}$ is very sensitive to electronic excitation either by electrons or $3.4 \mathrm{eV}$ photons, whereas $\mathrm{OH} / \mathrm{TiO}_{2}$ is orders of magnitude less capable of being desorbed or ionized by electrons or photons.

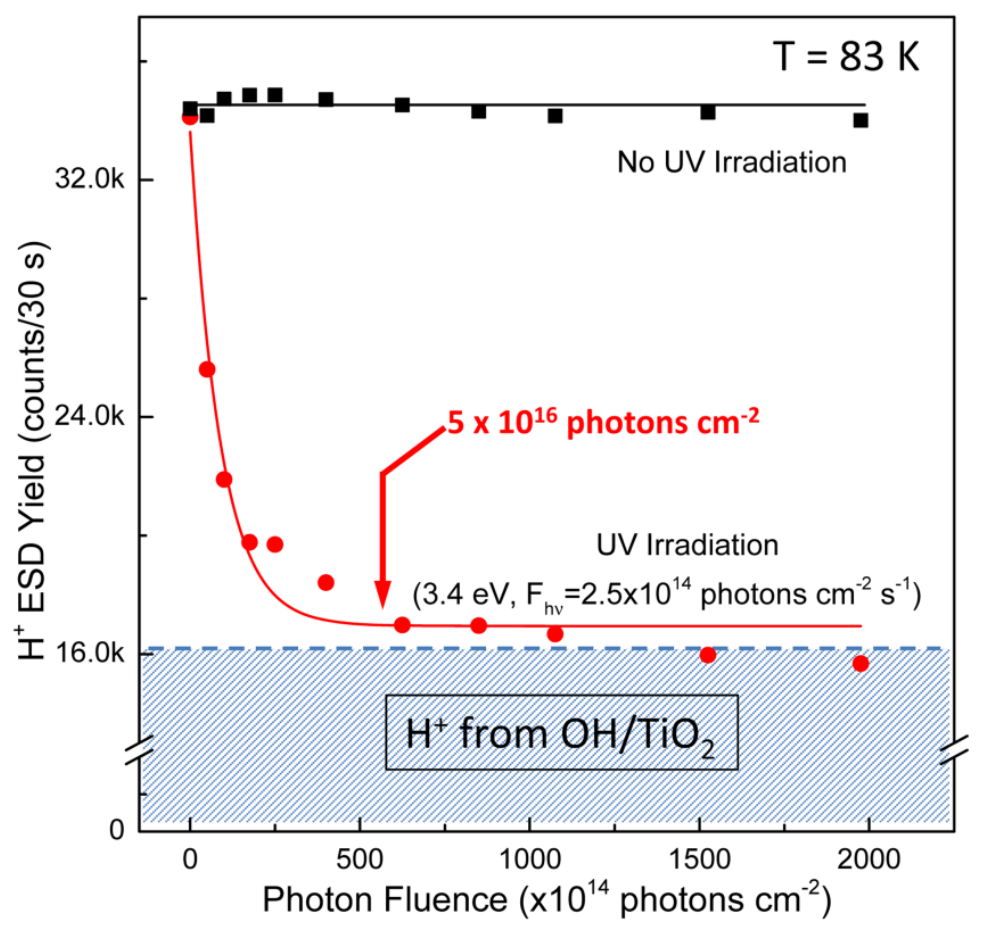

Figure 4.4: Photon stimulated desorption of $\mathrm{H} / \mathrm{TiO}_{2}$ with $3.4 \mathrm{eV}$ photons.

The reversibility of $\mathrm{H} / \mathrm{TiO}_{2}$ adsorption and photodesorption was tested by cycles of atomic $\mathrm{H}$ adsorption, followed by photodesorption with the full spectrum of a $500 \mathrm{~W} \mathrm{Hg}$ arc lamp (hv $<5.1 \mathrm{eV}$ ) employing an IR filter to eliminate crystal heating. In this work (Figure 4.5), the surface before the first cycle of atomic $\mathrm{H}$ adsorption is saturated by $\mathrm{OH}$ species by exposing to water at $320 \mathrm{~K}$. From two cycles of atomic $\mathrm{H}$ adsorption, followed 
by UV-induced $\mathrm{H}$ photodesorption, it was found that the addition and photodesorption of atomic $\mathrm{H}$ seems to be essentially reversible. $\mathrm{OH} / \mathrm{TiO}_{2}$ adsorption is essentially uninfluenced by UV excitation, allowing the reversibility studies to be accomplished without changing the $\mathrm{OH} / \mathrm{TiO}_{2}$ coverage.

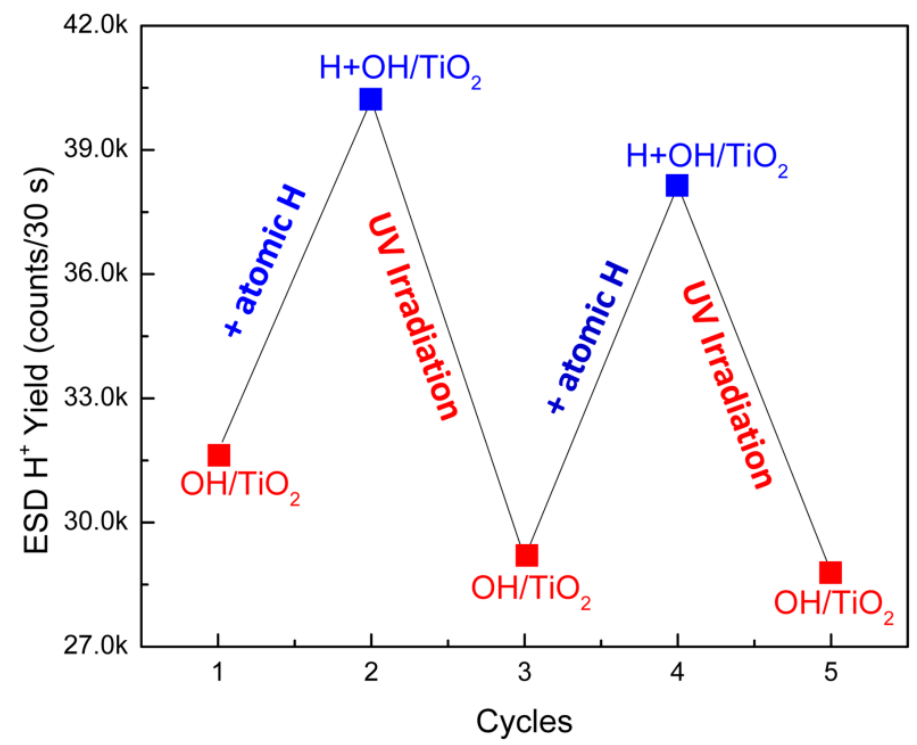

Figure 4.5: Reversible atomic $\mathrm{H}$ adsorption - $\mathrm{UV}$ photodesorption for $\mathrm{H} / \mathrm{TiO}_{2} ; \mathrm{H}$ is adsorbed on top of a saturated $\mathrm{OH} / \mathrm{TiO}_{2}$ surface.

\subsection{Summary and Future Directions}

Chemically-bound hydrogen, $\mathrm{H} / \mathrm{TiO}_{2}$, on the $\mathrm{TiO}_{2}(110)$ surface is produced by exposure to atomic $\mathrm{H}$ at $87 \mathrm{~K}$. This chemisorbed hydrogen differs significantly in its physical and chemical properties from $\mathrm{OH} / \mathrm{TiO}_{2}$ species produced from $\mathrm{H}_{2} \mathrm{O}$ adsorption. 
The $\mathrm{H} / \mathrm{TiO}_{2}$ species produces a normal beam of $\mathrm{H}^{+}$upon electron stimulated desorption whereas $\mathrm{OH} / \mathrm{TiO}_{2}$ species produce inclined $\mathrm{H}^{+} \mathrm{ESD}$ beams. This indicates that $\mathrm{H} / \mathrm{TiO}_{2}$ is normally-bonded to its adsorption site, whereas $\mathrm{OH} / \mathrm{TiO}_{2}$ exhibits an inclined O-H bond in the [1 $1 \overline{1} 0]$ direction. It would be good to examine the vibrational dynamics of Ti-OH species to determine if the $\mathrm{H}^{+}$-ESDIAD pattern elongation may be rationalized theoretically.

It is likely that $\mathrm{H} / \mathrm{TiO}_{2}$ is bound at $\mathrm{Ti}_{5 c}$ sites between the rows of bridged $\mathrm{O}$ atoms that constitute the outer surface of $\mathrm{TiO}_{2}(110)$. Therefore, future theoretical work of DFT calculations of the favorability of $\mathrm{Ti}_{5 c}-\mathrm{H}$ formation would be useful, as well as possible synergism between $\mathrm{Ti}_{5 c}-\mathrm{H}$ and neighboring Ti-OH species. Also, experimentally, studies have shown that $\mathrm{CO}^{[105]}$ and $\mathrm{CO}_{2}{ }^{[106]}$ can bind at $\mathrm{Ti}_{5 \mathrm{c}}$ sites and thus they can be good candidates for studying the atomic $\mathrm{H}$ binding sites via TPD experiments.

$\mathrm{H} / \mathrm{TiO}_{2}$ is thermally less stable than $\mathrm{OH} / \mathrm{TiO}_{2}$. By $~ 350 \mathrm{~K}, \mathrm{H} / \mathrm{TiO}_{2}$ has desorbed thermally as $\mathrm{H}_{2}$ whereas $\mathrm{OH} / \mathrm{TiO}_{2}$ begins to desorb as $\mathrm{H}_{2} \mathrm{O}$ only above $\sim 350 \mathrm{~K}$. Future theoretical work of DFT calculations of binding energies and activation energies for desorption from the site of adsorption would be helpful for $\mathrm{H} / \mathrm{TiO}_{2}$.

$\mathrm{H} / \mathrm{TiO}_{2}$ exhibits an extremely large cross section for ESD by $210 \mathrm{eV}$ electrons. This must indicate that $210 \mathrm{eV}$ electrons produce a large yield of e-h pairs in the $\mathrm{TiO}_{2}$ substrate causing efficient $\mathrm{H}$ desorption.

$\mathrm{H} / \mathrm{TiO}_{2}$ is highly sensitive to UV photodesorption using radiation capable of bandgap 
excitation. $\mathrm{H} / \mathrm{TiO}_{2}$ can be reversibly photodesorbed by $\mathrm{UV}$ and readsorbed using atomic $\mathrm{H}$ in the presence of a monolayer of $\mathrm{OH} / \mathrm{TiO}_{2}$. 


\section{References}

[1] A. Fujishima, K. Honda, Nature 1972, 238, 37.

[2] B. O'Regan, M. Grätzel, Nature 1991, 353, 737.

[3] X. Chen, S. S. Mao, Chem. Rev. 2007, 107, 2891-2959.

[4] O. K. Varghese, C. A. Grimes, J. Nanosci. Nanotechnol. 2003, 3, 277-293.

[5] D. C. Sorescu, W. A. Al-Saidi, K. D. Jordan, J. Chem. Phys. 2011, 135, 124701.

[6] R. Wang, K. Hashimoto, A. Fujishima, M. Chikuni, E. Kojima, A. Kitamura, M. Shimohigoshi, T. Watanabe, Nature 1997, 388, 431-432.

[7] T. Zubkov, D. Stahl, T. L. Thompson, D. A. Panayotov, O. Diward, J. T. Yates, Jr., J. Phys. Chem. B 2005, 109, 15454-15462.

[8] G. Lu, A. L. Linsebigler, J. T. Yates, Jr., Chem. Rev. 1995, 95, 735-758.

[9] U. Diebold, Surf. Sci. Rep. 2003, 48, 53-229.

[10] A. Fujishima, X. Zhang, D. A. Tryk, Surf. Sci. Rep. 2008, 63, 515-582.

[11] Z. Zhang, J. Lee, J. T. Yates, Jr., R. Bechstein, E. Lira, J. Ø. Hansen, S. Wendt, F. Besenbacher, J. Phys. Chem. C 2010, 114, 3059-3062.

[12] P. J. Møller, M. -C. Wu, Surf. Sci. 1989, 224 (265-276).

[13] C. Sánchez-Sánchez, J. A. Martín-Gago, M. F. López, Surf. Sci. 2013, 607 (159-163).

[14] S. Wendt, J. Matthiesen, R. Schaub, E. K. Vestergaard, E. Lægsgaard, F. Besenbacher, B. Hammer, Phys. Rev. Lett. 2006, 96, 066107.

[15] M.A. Henderson, W.S. Epling, C.H.F. Peden, C.L. Perkins, J. Phys. Chem. B 2003, 107, 534-545.

[16] C. L. Pang, R. Lindsay, G. Thronton, Chem. Sov. Rev. 2008, 37 (2328-2353).

[17] M. A. Henderson, Langmuir 1996, 12, 5093-5098.

[18] M. A. Henderson, Surf. Sci. 1998, 400, 203-219.

[19] L. M. Liu, B. McAllister, H. Q. Ye, P. Hu, J. Am. Chem. Soc. 2006, 128, 4017-4022.

[20] D. C. Sorescu, W. J. Lee, A. Al-saidi, K. D. Jordan, J. Chem. Phys. 2012, 137, 074704.

[21] S. C. Li, P. Jacobson, S. L. Zhao, X. Q. Gong, U. Diebold, J. Phys. Chem. C 2012, 116, 1887-1891.

[22] Z. Zhang, O. Bondarchuk, B. D. Kay, J. M. White, Z. Dohnalek, J. Phys. Chem. B 2006, 110, 21840-21845. 
[23] M.B. Hugenschmidt, L. Gamble, C.T. Campbell, Surf. Sci. 1994, 302, 329-340.

[24] I. M. Brookes, C. A. Muryn, G. Thornton, Phys. Rev. Lett. 2001, 87, 266103.

[25] R. Schaub, P. Thostrup, N. Lopez, E. Laegsgaard, I. Stensgaard, J. K. Nørskov, F. Besenbacher, Phys. Rev. Lett. 2001, 87 (266104).

[26] S. Wendt, R. Schaub, J. Matthiesen, E. K. Vestergaard, E. Wahlström, M. D. Rasmussen, P. Thostrup, L. M. Molina, E. Laegsgaard, I. Stensgaard, B. Hammer, F. Besenbacher, Surf. Sci. 2005, 598, 226-245.

[27] M. A. Henderson, Surf. Sci. 1996, 355, 151-166.

[28] N. G. Petrik, G. A. Kimmel, Phys. Rev. Lett. 2007, 99, 196103.

[29] J. Lee, D. C. Sorescu, X. Deng, K. D. Jordan, J. Phys. Chem. Lett. 2012, 4, 53-57.

[30] J. -M. Pan, B. L. Maschhoff, U. Diebold, T. E. Madey, J. Vac. Sci. Technol. A 1992, 10, 2470.

[31] W. Unterberger, T. J. Lerotholi, E. A. Kroger, M. J. Knight, D. A. Duncan, D. Kreikemeyer-Lorenzo, K. A. Hogan, D. C. Jackson, R. Wlodarczyk, M. Sierka, J. Sauer, D. P. Woodruff, Phys. Rev. B 2011, 84, 115461.

[32] D. A. Panayotov, J. T. Yates, Jr., J. Phys. Chem. C 2007, 111, 2959-2964.

[33] X. -L. Yin, M. Calatayud, H. Qiu, Y. Wang, A. Birkner, C. Minot, Ch. Wöll, ChemPhysChem 2008, 9 , 253-256.

[34] Y. Du, N. G. Petrik, N. A. Deskins, Z. Wang, M. A. Henderson, G. A. Kimmel, I. Lyubinetsky, Phys. Chem. Chem. Phys. 2012, 14, 3066-3074.

[35] S. Suzuki, K. Fukui, H. Onishi, Y. Iwasawa, Phys. Rev. Lett. 2000, 84, 2156-2159.

[36] M. C. Torquemada, J. L. de Segovia, J. Vac. Sci. Technol. A 1994, 12, 2318-2322.

[37] C. L. Greenwood, E. M. Williams, G. Thornton, S. L. Bennett, E. Roman, J. L. de Segovia, M. C. Torquemada, Surf. Sci. 1993, 287, 386-390.

[38] J. L. de Segovia, M. C. Torquemada, E. Roman, J. Phys.: Condens. Matter 1993, 5, A139-A142.

[39] I. Cocks, Q. Guo, E. M. Williams, Surf. Sci. 1997, 390, 119-125.

[40] M. C. Torquemada, J. L. de Segovia, Vacuum 1995, 46, 1219-1222.

[41] M. C. Torquemada, J. L. de Segovia, E. Roman, Surf. Sci. 1995, 337, 31-39.

[42] M. A. Henderson, S. Otero-Tapia, M. E. Castro, Surf. Sci. 1998, 412-13, 252-272.

[43] B. Yakshinskly, M. Akbulut, T. E. Madey, Surf. Sci. 1997, 390, 132-139.

[44] V. N. Ageev, S. Solovev, Phys. Solid State 2000, 42, 2159-2163.

[45] Q. Guo, I. Cocks, E. M. Williams, J. Chem. Phys. 1997, 106, 2924-2931.

[46] U. Diebold, T. E. Madey, J. Vac. Sci. Technol. A 1992, 10, 2327. 
[47] C. D. Lane, N. G. Petrik, T. M Orlando, G. A. Kimmel, J. Phys. Chem. C 2007, 111, 16319-16329.

[48] C. D. Lane, N. G. Petrik, T. M Orlando, G. A. Kimmel, J. Chem. Phys. 2007, 127, 224706.

[49] J. Lee, Z. Zhang, J. T. Yates, Jr., Phys. Rev. B 2009, 79, 081408.

[50] Z. Zhang, J. T. Yates, Jr., J. Phys. Chem. Lett. 2010, 1, 2185-2188.

[51] Z. Zhang, J. T. Yates, Jr., J. Phys. Chem. C 2010, 114, 3098-3101.

[52] R. D. Ramsier, J. T. Yates, Jr., Surf. Sci. Rep. 1991, 12, 243-378.

[53] T. E. Madey, D. E. Ramaker, R. Stockbauer, Ann. Rev. Phys. Chem. 1984, 35, 215-240.

[54] D. Menzel, Nucl. Instr. and Meth. in Phys. Res. B 1995, 101, 1-10.

[55] P. A. Redhead, Vacuum 1997, 48, 585-596.

[56] M. L. Knotek, P. J. Feibelman, Phys. Rev. Lett. 1978, 40, 964.

[57] Z. Zhang, K. Cao, J. T. Yates, Jr., J. Phys. Chem. Lett. 2013, 4, 674-679.

[58] http://www.newport.com/Flood-Exposure-Sources/378214/1033/info.aspx.

[59] J. T. Yates, Jr., Experimental Innovations in Surface Science. Springer-Verlag: 1997; p 604.

[60] T. L. Thompson, J. T. Yates, Jr., Chem. Rev. 2006, 106, 4428-4453.

[61] M.A. Henderson, Surf. Sci. Reports 2011, 66, 185-297.

[62] G. Lu, A. L. Linsebigler, J. T. Yates, Jr., J. Phys. Chem. 1994, 98, 11733-11738.

[63] O. Bikondoa, C. L. Pang, R. Ithnin, C. A. Muryn, H. Onishi, G. Thornton, Nat. Mater. 2006, 5, 189-192.

[64] S. Wendt, P. T. Sprunger, E. Lira, G. K. H. Madsen, Z. Li, J. Ø. Hansen, J. Matthiesen, A. Blekinge-Rasmussen, E. Lægsgaard, B. Hammer, F. Besenbacher, Science 2008, 320, 1755-1759.

[65] P. Krüger, J. Jupille, S. Bourgeois, B. Domenichini, A. Verdini, L. Floreano, A. Morgante, Phys. Rev. Lett. 2012, 108, 126803.

[66] C. M. Yim, C. L. Pang, G. Thornton, Phys. Rev. Lett. 2010, 104, 036806.

[67] K. Mitsuhara, M. Okumura, A. Visikovskiy, M. Takizawa, Y. Kido, J. Chem. Phys. 2012, 136, 124707.

[68] R. L. Kurtz, R. Stockbauer, T. E. Madey, E. Roman, J. L. de Segovia, Surf. Sci. 1989, 218, 178-200.

[69] N. G. Petrik, Z. Zhang, Y. Du, Z. Dohnalek, I. Lyubinetsky, G. A. Kimmel, J. Phys. Chem. C 2009, 113, 12407-12411.

[70] L. M. Liu, P. Crawford, P. Hu, Prog. Surf. Sci. 2009, 84, 155-176.

[71] Z. Dohnalek, I. Lyubinetsky, R. Rousseau, Prog. Surf. Sci. 2010, 85, 161-205.

[72] C. Di Valentin, G. Pacchioni, A. Selloni, J. Phys. Chem. C 2009, 113, 20543-20552. 
[73] A. G. Thomas, W. R. Flavell, A. R. Kumarasinghe, A. K. Mallick, D. Tsoutsou, G. C. Smith, R. Stockbauer, S. Patel, M. Gratzel, R. Hengerer, Phys. Rev. B 2003, 67, 035110.

[74] P. Krüger, S. Bourgeois, B. Domenichini, H. Magnan, D. Chandesris, P. Le Fèvre, A. M. Flank, J. Jupille, L. Floreano, A. Cossaro, A. Verdini, A. Morgante, Phys. Rev. Lett. 2008, 100, 055501.

[75] E. Serwicka, M. W. Schlierkamp, R. N. Schindler, Z. Naturforsch. 1981, 36a, 226-232.

[76] S. Chrétien, H. Metiu, J. Phys. Chem. C 2011, 115, 4696-4705.

[77] N. A. Deskins, R. Rousseau, M. Dupuis, J. Phys. Chem. C 2011, 115, 7562-7572.

[78] T. Shibuya, K. Yasuoka, S. Mirbt, B. Sanyal, J. Phys.: Condens. Matter 2012, 24, 435504.

[79] P. M. Kowalski, M. F. Camellone, N. N. Nair, B. Meyer, D. Marx, Phys. Rev. Lett. 2010, 105, 146405.

[80] A. C. Papageorgiou, N. S. Beglitis, C. L. Pang, G. Teobaldi, G. Cabailh, Q. Chen, A. J. Fisher, W. A. Hofer, G. Thronton, Proc. Natl. Acad. Sci. USA 2010, 107, 2391-2396.

[81] T. Minato, Y. Sainoo, Y. Kim, H. S. Kato, K. Aika, M. Kawai, J. Zhao, H. Petek, T. Huang, W. He, B. Wang, Z. Wang, Y. Zhao, J. L. Yang, J. G. Hou, J. Chem. Phys. 2009, 130, 124502.

[82] C. Di Valentin, G. Pacchioni, A. Selloni, Phys. Rev. Lett. 2006, 97, 166803.

[83] J. Ahner, D. Mocuta, J.T. Yates, Jr., J. Vac. Sci. Technol. A 1999, 17, 2333-2338.

[84] R. T. Zehr, M. A. Henderson, Surf. Sci. 2008, 602, 1507-1516.

[85] B. Bonelli, M. Cozzolino, R. Tesser, M. Di Serio, M. Piumetti, E. Garrone, E. Santacesaria, J. Catal. 2007, 246, 293-300.

[86] T. Bezrodna, G. Puchkovska, V. Shimanovska, I. Chashechnikova, T. Khalyavka, J. Baran, Appl. Surf. Sci. 2003, 214, 222-231.

[87] J. Lee, Z. Zhang, J.T. Yates, Jr., Phys. Rev. B 2009, 79, 081408(R).

[88] A. T. Paxton, L. Thiên-Nga, Phys. Rev. B 1998, 57, 1579-1584.

[89] S.-i. Tanaka, K. Mase, S.-i. Nagaoka, Surf. Sci. 2004, 572, 43-58.

[90] U. Diebold, T. E. Madey, Phys. Rev. Lett. 1994, 72, 1116-1119.

[91] M. Akbulut, N. J. Sack, T. E. Madey, J. Chem. Phys. 1995, 103, 2202-2215.

[92] O. Dulub, M. Batzill, S. Solovev, E. Loginova, A. Alchagirov, T. E. Madey, U. Diebold, Science 2007, 317, 1052-1056.

[93] L. R. Merte, G. Peng, R. Bechstein, F. Rieboldt, C. A. Farberow, L. C. Grabow, W. Kudernatsch, S. Wendt, E. Lægsgaard, M. Mavrikakis, F. Besenbacher, Science 2012, 336, 889-893.

[94] D. A. Panayotov, S. P. Burrows, J. T. Yates, Jr., J. R. Morris, J. Phys. Chem. C 2011, 115, 22400-22408. 
[95] S. Khoobiar, J. Phys. Chem. 1964, 68, 411-412.

[96] F. Boccuzzi, A. Chiorino, G. Ghiotti, E. Guglielminotti, Langmuir 1989, 5, 66-70.

[97] M. D. Marcinkowski, A. D. Jewell, M. Stamatakis, M. B. Boucher, E. A. Lewis, C. J. Murphy, G. Kyriakou, E. C. H. Sykes, Nat. Mater. 2013, 12, 523-528.

[98] A. Al-Mahboob, E. Muller, A. Karim, J. T. Muckerman, C. V. Ciobanu, P. Sutter, J. Am. Chem. Soc. 2012, $134,10381-10384$.

[99] X. Chen, L. Liu, P. Y. Yu, S. S. Mao, Science 2011, 331, 746-750.

[100] L. Zhang, R. Persaud, T. E. Madey, Phys. Rev. B 1997, 56, 10549-10557.

[101] X. Lai, T. P. St Clair, M. Valden, D. W. Goodman, Prog. Surf. Sci. 1998, 59, 25-52.

[102] V. A. Bondzie, S. C. Parker, C.T. Campbell, Catal. Lett. 1999, 63, 143-151.

[103] F. Cosandey, T. E. Madey, Surf. Rev. Lett. 2001, 8, 73-93.

[104] M. A. Henderson, Surf. Sci. 1999, 419, 174-187.

[105] A. L. Linsebigler, G. Lu, J. T. Yates, Jr., J. Phys. Chem. 1995, 103, 9438-9443.

[106] T. L. Thompson, O. Diwald, J. T. Yates, Jr., J. Phys. Chem. B 2003, 107, 11700-11704. 


\section{Appendix}

\section{Appendix A: UV-Vis Spectra of Selected Longpass Filters and Bandpass}

\section{Filters}

The longpass filters and bandpass filters were tested using a Hewlett-Packard 8452A

Diode Array Spectrophotometer. Some selected spectra are shown in Figure A1 and A2.

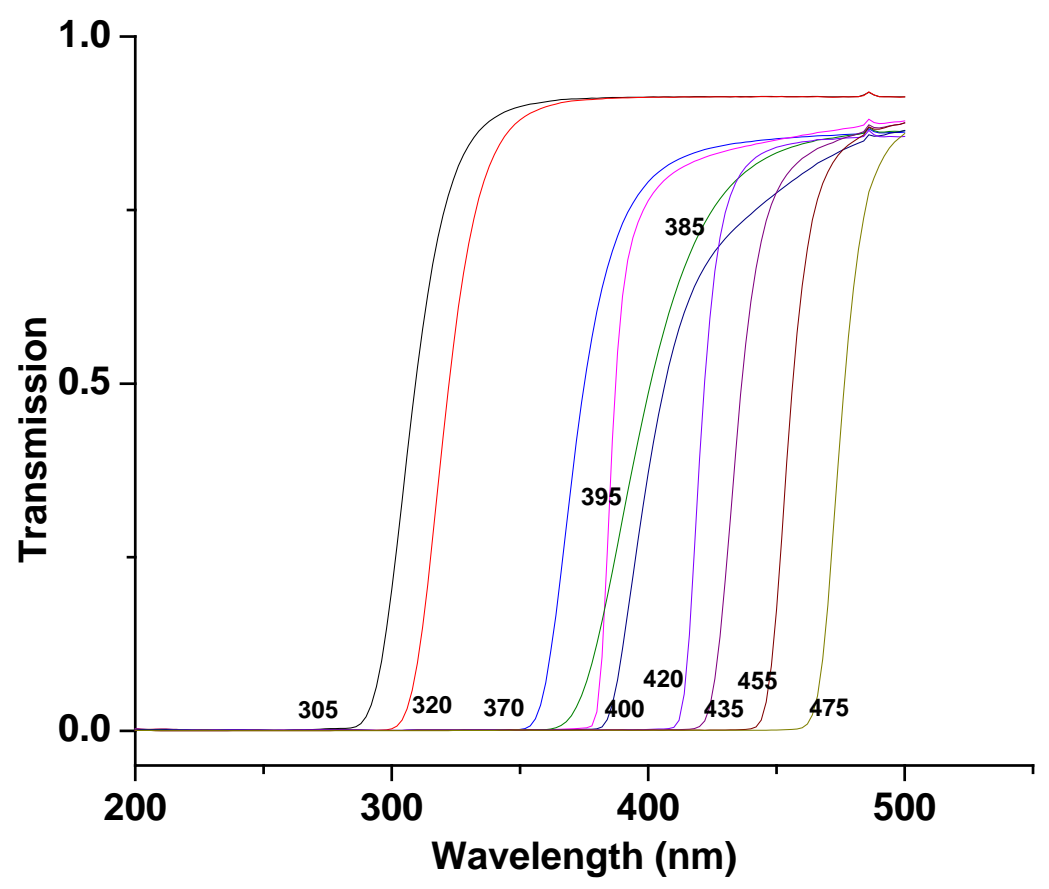


Figure A1: UV-Vis spectra of longpass filters; cut-off wavelengths are marked respectively in the figure.

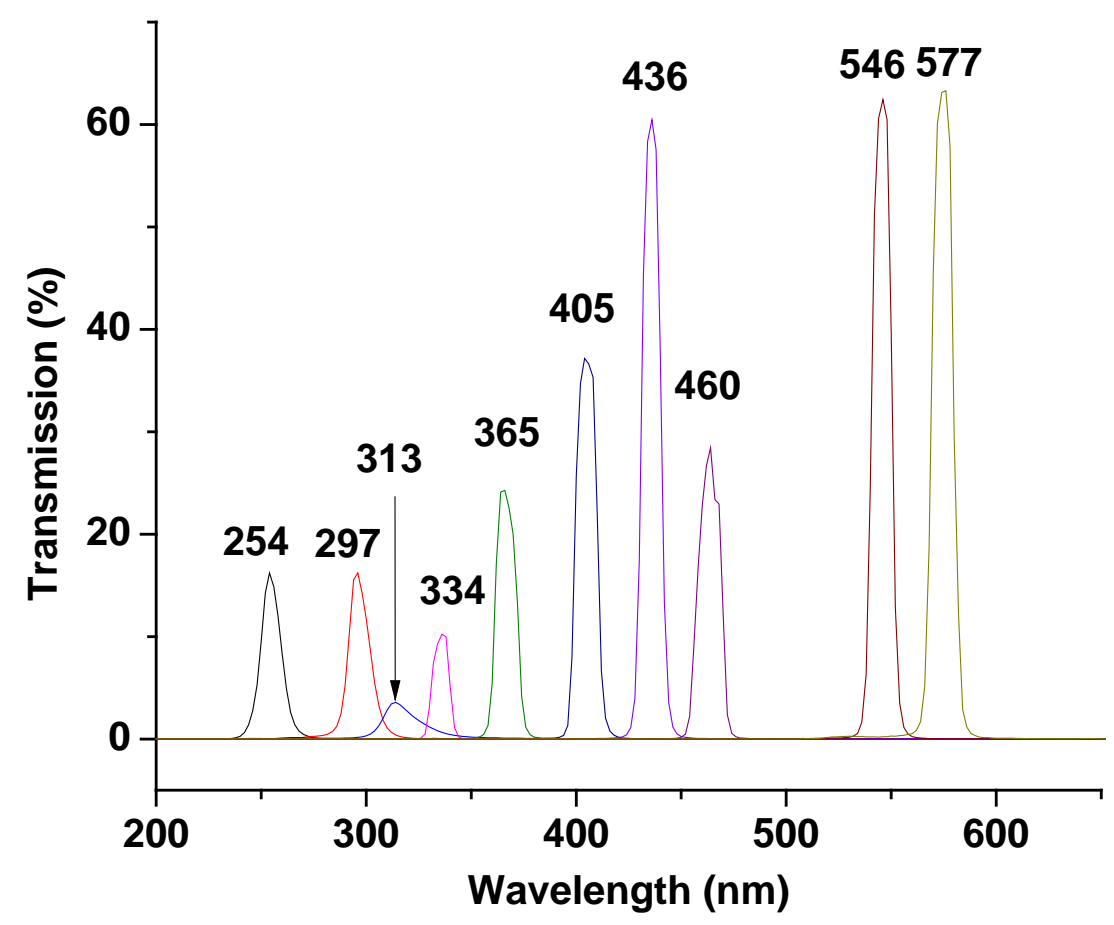

Figure A2: UV-Vis spectra of bandpass filters; center wavelengths are marked respectively in the figure. 